IZA DP No. 8012

Key Players in Co-Offending Networks

Matthew J. Lindquist

Yves Zenou

February 2014

Forschungsinstitut zur Zukunft der Arbeit Institute for the Study of Labor 


\title{
Key Players in Co-Offending Networks
}

\author{
Matthew J. Lindquist \\ SOFI, Stockholm University
}

Yves Zenou

Stockholm University, IFN and IZA

\section{Discussion Paper No. 8012 \\ February 2014}

\author{
IZA \\ P.O. Box 7240 \\ 53072 Bonn \\ Germany \\ Phone: +49-228-3894-0 \\ Fax: +49-228-3894-180 \\ E-mail: iza@iza.org
}

\begin{abstract}
Any opinions expressed here are those of the author(s) and not those of IZA. Research published in this series may include views on policy, but the institute itself takes no institutional policy positions. The IZA research network is committed to the IZA Guiding Principles of Research Integrity.

The Institute for the Study of Labor (IZA) in Bonn is a local and virtual international research center and a place of communication between science, politics and business. IZA is an independent nonprofit organization supported by Deutsche Post Foundation. The center is associated with the University of Bonn and offers a stimulating research environment through its international network, workshops and conferences, data service, project support, research visits and doctoral program. IZA engages in (i) original and internationally competitive research in all fields of labor economics, (ii) development of policy concepts, and (iii) dissemination of research results and concepts to the interested public.
\end{abstract}

IZA Discussion Papers often represent preliminary work and are circulated to encourage discussion. Citation of such a paper should account for its provisional character. A revised version may be available directly from the author. 


\title{
ABSTRACT
}

\section{Key Players in Co-Offending Networks ${ }^{*}$}

\begin{abstract}
We study peer effects in crime by analyzing co-offending networks. We first provide a credible estimate of peer effects in these networks equal to 0.17 . This estimate implies a social multiplier of 1.2 for those individuals linked to only one co-offender and a social multiplier of 2 for those linked to three co-offenders. We then provide one of the first empirical tests of the key player policy in a real world setting. This policy defines a micro-founded strategy for removing the criminal from each network that reduces total crime by the largest amount. Using longitudinal data, we are able to compare the theoretical predictions of the key player policy with real world outcomes. By focusing on networks for which the key player has disappeared over time, we show that the theoretical predicted crime reduction is close to what is observed in the real world. We also show that the key player policy outperforms other reasonable police policies such as targeting the most active criminals or targeting criminals who have the highest betweenness or eigenvector centrality in the network. This indicates that behavioral-based policies can be more efficient in reducing crime than those based on algorithms that have no micro-foundation.
\end{abstract}

\section{NON-TECHNICAL SUMMARY}

We provide one of the first empirical tests of the key player policy in a real world setting. This policy defines a micro-founded strategy for removing the criminal from each network that reduces total crime by the largest amount. Using Swedish data, we show that, on average, a key-player policy reduces crime by 37 percent and outperforms other reasonable police policies such as targeting the most active criminals or targeting criminals who have the highest betweenness or eigenvector centrality in the network.

JEL Classification: A14, K42, Z13

Keywords: crime, social networks, peer effects, social multiplier, key player, crime policies

Corresponding author:

Yves Zenou

Stockholm University

Department of Economics

10691 Stockholm

Sweden

E-mail: yves.zenou@ne.su.se

\footnotetext{
* We would like to thank Yann Bramoullé, Habiba Djebbari, Randi Hjalmarsson, Xiaodong Liu, Eleonora Patacchini and seminar participants at the IZA Workshop on Networks 2013, the UCL-NHH Crime Workshop 2013, GREQAM (Aix-Marseille University) and the Swedish Institute for Social Research. Matthew Lindquist gratefully acknowledges financial support from the Swedish Council for Health, Working Life and Welfare (FORTE).
} 


\section{Introduction}

In her article in the New York Times on June 11, 2013, the journalist Monica Davey documents that Chicago has witnessed an important drop in shootings and crime. Killings in 2013 have dipped to a level not seen since the early 1960s. So far in 2013, Chicago homicides, which outnumbered slayings in the larger cities of New York and Los Angeles last year, are down by 34 percent from the same period in 2012. Her explanation of this important decrease in crime is that, in recent months, as many as 400 officers a day, working overtime, have been dispatched to just 20 small zones deemed the city's most dangerous. The police say they are tamping down retaliatory shootings between gang factions by using a comprehensive analysis of the city's tens of thousands of suspected gang members, the turf they claim and their rivalries. The police are also focusing on more than 400 people they have identified as having associations that make them the most likely to be involved in a murder, as a victim or an offender.

The aim of this paper is to further investigate this issue by studying how targeting criminals embedded in some network can have important effects on crime reduction. To do this, we address two important questions concerning the role of social interactions and social networks in the etiology of crime. First, we investigate the role of peer effects in crime. Second, we test the empirical relevance of the "key player" policy in an important, real world setting, where the aim is to target the criminal who once removed from the network reduces total crime the most. We also compare the predictive performance of the key player to the performance of other policies based on more traditional measure of network centrality and to reasonable policies such as the one that targets the most active criminals.

To be more precise, we use Swedish data on co-offending networks. We have access to the official police register of persons who are suspected of committing a crime and, if relevant, with whom they are suspected of committing a crime. These data allow us to characterize a set of 
real world networks of criminal offenders where a link is defined when two persons are suspected of co-offending together. We use data from two three-year periods; the first period is from 2000 to 2002 , while the second is from 2003 to 2005 .

Looking at simple descriptive statistics of these co-offending networks in both periods, we find that they differ from, for example, networks of co-authors because they display a much higher clustering coefficient and a higher average distance between co-offenders. We show that the degree distribution is skewed somewhat to the left of the random distribution. We explore this apparent non-randomness in link formation and find that women and immigrants form more links than one would expect if links were simply formed at random and we observe a strong tendency towards homophily. When forming new links, males have a higher odds of linking with another male as opposed to forming a new link with a female, while those born abroad have a higher odds of linking to another immigrant as opposed to a native born. We also find that people sort along income, education, age, and county of residence. Age, county of residence, and country of origin are the strongest predictors of link formation.

Our theoretical framework is based on the models of criminal networks and key player policies of Ballester et al. (2006, 2010). These models provide a behavioral foundation for our empirical analysis, including an equation for estimating peer effects and a formula for calculating the key player policy. The latter is Ballester et al.'s measure of intercentrality.

We find that that there are strong peer effects in co-offending networks in Sweden. We find an estimate of peer effects of 0.17 , which means that, having co-offended with only one person, increases my own propensity of committing crime by $20 \%$ (the social multiplier effect) while, if the number of co-offenders is three, it increases by $100 \%$.

We then provide one of the first empirical tests of the key player policy in a real world setting. In our data, $67 \%$ of all key players are not the most active criminal in their own networks; 
$34 \%$ do not have the highest eigenvector centrality; and 50\% do not have the highest betweenness centrality. Using our data, the theoretical model of the key player predicts that the population weighted average reduction in crime for the mean network (with size $=62$ ) is equal to $38 \%$. We also determine by how much the key player policy outperforms other reasonable policies such targeting the most active criminal.

We test these predictions against the true outcome observed in our Period 2 data. We start by calculating the total change in actual crime experienced by each network of individuals. Those who do not show up in our Period 2 data (i.e., those who are not suspected of committing a crime together with a co-offender in Period 2) are assigned zeros in Period 2. In particular, by focusing on networks for which the key player has "disappeared" in Period 2 (because, for example, he/she has died during the relevant time period or has been placed in prison), we show that the theoretical predicted crime reduction is close to what is observed in the real world.

Finally, we show that, in the real-world, the key player policy outperforms the random player policy by $6.4 \%$. The key player policy also outperforms the policy of removing the most active player by $2.4 \%$, the policy of removing the player with the highest betweenness centrality by $6.3 \%$, and the policy of removing the player with the highest eigenvector centrality by $18 \%$. These results seem to indicate that behavioral-based policies can be more efficient in reducing crime than those based on algorithms that have no micro-foundations.

\subsection{Related Literature and Original Contributions}

There is a growing empirical literature suggesting that peer effects are important in criminal activities. In the non-economic literature, it is well-established that delinquency is, to some extent, a group phenomenon, and the source of crime and delinquency is located in the intimate social networks of individuals (see e.g. Sutherland, 1947; Haynie, 2001; Sarnecki, 2001; Warr, 
2002). Indeed, delinquents often have friends who have themselves committed several offences, and social ties among delinquents are seen as a means whereby individuals exert an influence over one another to commit crimes.

In the economic literature, Glaeser et al. (1996) were one of the first to study social interactions in crime. Their results suggest that the amount of social interactions is highest in petty crimes and moderate in more serious crimes. Ludwig et al. (2001) and Kling et al. (2005) study the relocation of families from high- to low-poverty neighborhoods using data from the Moving to Opportunity (MTO) experiment. They find that this policy reduces juvenile arrests for violent offences by 30 to 50 percent, relative to a control group. Bayer et al. (2009) consider the influence that juvenile offenders serving time in the same correctional facility have on each other's subsequent criminal behavior. They also find strong evidence of learning effects in criminal activities since exposure to peers with a history of committing a particular crime increases the probability that an individual who has already committed the same type of crime recidivates that crime.

Drago and Galbiati (2012) use the 2006 Italian prison pardon to identify peer effects among inmates post release. They define peer groups by facility and nationality for non-Italian born inmates and facility and region of origin for Italian born inmates. They find that the effect on individual recidivism due to an increase in peers' residual sentence length is just as large as the effect due to own residual sentence length. ${ }^{1}$ Thus, their estimate of the social multiplier in crime among former inmates is 2 .

\footnotetext{
${ }^{1}$ Residual sentence length is the amount of time that an inmate had left to serve in the absence of the pardon. This residual sentence would be added to any new sentence received within 5 years from the pardon. This creates exogenous variation in the sentence length faced by otherwise similar offenders. That is, it creates variation in the incentive to recidivate. See also Drago, Galbiati and Vertova (2009).
} 
More recently, Damm and Dustmann (2014) investigate the following question: Does growing up in a neighborhood in which a relatively high share of youth has committed crime increase the individual's probability of committing crime later on? To answer this question, Damm and Dustmann exploit a Danish natural experiment that randomly allocates parents of young children to neighborhoods with different shares of youth criminals. With area fixed effects, their key results are that one standard deviation increase in the share of youth criminals in the municipality of initial assignment increases the probability of being charge with an offense at the age $18-21$ by 8 percentages point (or 23 percent) for men. This neighborhood crime effect is mainly driven by property crime. ${ }^{2}$

Using a more structural approach, Patacchini and Zenou (2012) and Liu et al. (2012) also test peer effects in crime using the National Longitudinal Survey of Adolescent Health (AddHealth) where students in schools between grades in grades 7-12 have friendship networks and self-report different types of crimes they have committed. The authors find that, for an average group of 4 best friends, a standard deviation increase in the level of delinquent activity of each of the peers translates into a roughly 17 percent increase of a standard deviation in the individual level of activity.

Our first contribution to this literature is that we provide a credible estimate of peer effects in co-offending networks using real world crime data. We use two instrumental variables in a two-stage least squares (2SLS) framework to estimate the endogenous peer effect net of contextual effects. We include county fixed effects and network fixed effects to address

\footnotetext{
${ }^{2}$ See also the very interesting paper by Corno (2012) who study peer effects in crime among the homeless in Milan. To instrument for peer effects, she uses rainfall since it fosters concentration of homeless individuals in sheltered places and increases the probability of meetings. Corno finds that the probability of arrest decreases by 16 percentage points with the network size.
} 
correlated effects and endogenous sorting into networks. We also include individual level and average group level control variables.

Our two instruments solve the reflection problem (Manski 1993) by making use of the fact that the networks we study are incomplete, i.e. everyone is not connected to everyone else. We use both intransitive triads (Bramoullé et al. 2009) and variation in the number of links (Lee et al. 2010; Liu and Lee 2010) as instrumental variables to identify peer effects. These instruments provide exclusion restrictions that solve the simultaneity issue. Furthermore, under the assumption that network formation is conditionally exogenous, these instruments also solve the more traditional endogeneity problem due to unobservable heterogeneity. We provide three pieces of evidence in support of this assumption: (i) an over-identifying restriction test, (ii) a direct test for endogenous network formation (Goldsmith-Pinkham and Imbens 2013), and (iii) an alternative estimate using lagged crime as a control for unobservable heterogeneity. We also run a nonrandom placebo test (falsification exercise) in the spirit of Card and Giuliano's (2013) "fake friends" exercise and we propose a series of tests for "hidden links". These tests supply further support for our methods and results.

We find that there are strong peer effects in co-offending networks in Sweden. We find an estimate of peer effects of 0.17 . This estimate implies a social multiplier of 1.2 for those individuals linked to only one co-offender and a social multiplier of 2 for those linked to three cooffenders. The average, within network social multiplier is 1.7. Importantly, our estimated peer effects and social multiplier are very much in line with those reported by Drago and Galbiati (2012) whose experiment is (arguably) the inverse of our own.

The problem of identifying key players in a network is an old one, at least in the sociological literature. Different measures of network centralities have been proposed to assert the descriptive and/or prescriptive suitability of each of these measures to different situations 
(see, in particular, Wasserman and Faust, 1994). ${ }^{3}$ Borgatti $(2003,2006)$ was among the first researcher to really investigate the issue of key players, which is based on measuring explicitly the contribution of a set of actors to the cohesion of a network. The basic strategy is to take any whole network property, such as density or maximum flow, and derive a centrality measure by deleting nodes and measuring the change in the network property. ${ }^{4}$ The main problem with this approach is that the network centralities that define key players are simple formulas calculated by algorithms (for example, the betweenness centrality or the eigenvector centrality) but the behavior of agents is not modeled. ${ }^{5}$ Ballester et al. $(2006,2010)$ and Ballester and Zenou (2014) have proposed a theoretical model of the key player policy that is the result of a planner's maximization of total crime reduction. They give an exact theoretical measure called the intercentrality measure, which determines who is the key player in each network. ${ }^{6}$ Liu et al. (2012) were the first to test the key player policy using the AddHealth data mentioned above. Compared to a policy that randomly removes delinquents from the network, they show that a key player policy engenders a crime reduction that can be as large as 35 percent.

We pursue this line of research by testing the importance of the key player policy using co-offending networks. Because of the panel aspect of our data, we are the first to be able to exactly test the theoretical predictions of the intercentrality measure in terms of crime reduction against the true outcome observed in our Period 2 data. This is a unique test never performed

\footnotetext{
${ }^{3}$ In more recent work, Mastrobuoni and Patacchini (2012) study detailed network data concerning 800 members of the Italian American mafia active in the United States during the 1950's and 1960's. They are able to calculate measures of network centrality and describe the characteristics of the more central actors. They map out a very hierarchical structure that depends strongly on kinship and country of birth. Centrality peaks around age 60, which is consistent with a "generational" hierarchy in family oriented networks. It also appears that more central mafia families used strategic marriages between "trusted" families in order to maintain their family's network centrality.

${ }^{4}$ Tayebi et al. (2011) propose a similar procedure for co-offending networks.

${ }^{5}$ Even in sociology, Carrington (2011, p. 245) has criticized this approach by questioning the usefulness in picking out "key" and/or "central" actors.

${ }^{6}$ The economics of networks is a growing field. See, in particular, Jackson (2008), Ioannides (2013) and Jackson and Zenou (2014).
} 
before. For that, we focus on networks for which the key player does not show up in our Period 2 data. We show that the intercentrality measure is actually a good predictor of crime reduction since it matches what is observed in the real world. In the last part of the paper, we show that the key player policy outperforms a policy of removing the most active player by $2.4 \%$, the policy of removing the player with the highest betweenness centrality by $6 \%$, and the policy of removing the player with the highest eigenvector centrality by $18 \%$. These results seem to indicate that behavioral-based policies can be more efficient in reducing crime than those based on algorithms that have no micro-foundations

\subsection{Outline of the Paper}

The remainder of this paper unfolds as follows. In the next section, we describe our dataset and provide some individual descriptive statistics. In Section 3, we perform the same exercise but at the network level. We also discuss how we can break our giant component into a number of smaller communities. Section 4 is devoted to the theoretical framework where we expose our model of peer effects as well as the key player policy. In Section 5, we present the econometric model corresponding to the best-reply function of the theoretical model and discuss identification issues. Section 6 displays our empirical results of the peer-effect model and presents different exogeneity tests as well as robustness checks. In Section 7, we identify who the key player is in each network and give his/her main characteristics. Section 8 is devoted to our empirical test of the key player policy. Finally, Section 9 concludes.

\section{Crime Networks Data}

The data used in this paper were assembled as follows. Statistics Sweden began by drawing a 25 percent random sample from Sweden's Multigenerational Register, which includes all persons 
born from 1932 onwards who have lived in Sweden at any time since 1961. Mothers and fathers, brothers and sisters, and children of each person in the 25 percent random sample were matched onto the sample. This resulted in a sample which includes approximately $70 \%$ of the Swedish population. For each individual in this sample we have register data concerning gender, year of birth, education, income, employment in November, months on welfare, number of sick days, marital status, children, country of birth ${ }^{7}$ and county of residence.

The data set created by Statistics Sweden was then matched with Sweden's official crime register by Sweden's National Council for Crime Prevention. Thus, for all people in our data set, we also have a full record of their criminal convictions (belastningsregistret). More importantly, for the purposes of this paper, we also have access to the official police register of persons who are suspected of committing a crime (misstänktsregistret). In this register, the police actually keep records of who is suspected of committing a crime with whom. This is where we get our information concerning network connections, henceforth "links". Both the convictions data and suspects data include crime type, crime date, and sanction received.

To be clear, our outcome variable, Crime $_{i t}$, is the sum of individual $i$ 's convictions during period $t$ (both solo offenses and co-offenses), while links are based on whom they are suspected of committing a co-offense with.

Co-offenses account for $24 \%$ of all crimes in our suspects data and $42 \%$ of all offenders have at least one co-offender. In total, this group of crime suspects is responsible for $74 \%$ of all of the crimes in our data set. This implies that individuals who are involved in co-offending behavior commit (on average) two solo offenses for every co-offense. It also means that those not

\footnotetext{
7 Actually, we have information on region of birth; Sweden, other Nordic, EU27 (excluding Nordic), Europe (excluding EU27 and Nordic), Soviet Union, Africa, Asia, North America, South America, Oceania, Stateless (e.g., Palestine), and unknown.
} 
involved in the co-offending networks that we study in this paper have (on average) much lower offending rates than those we do study.

In this paper, we use the police's suspects register to study co-offending networks during two separate, three-year periods. The first period is from 2000 to 2002 . The second is from 2003 to 2005 . We eliminate suspects under the age of 15 . We also drop those for whom suspicions could not be substantiated in order to focus on "true" crime suspects and not just unlucky bystanders who happened to be in the wrong place at the wrong time. Lone offenders, isolated pairs and triplets are excluded from our network data. Thus, each network (subgraph) in our network data set (graph) includes at least 4 individuals.

In our Period 1 data, individuals have between 1 and 25 unique co-offenders. In our Period 2 data, however, some people have as many as 100 unique co-offenders. To make the data in these two periods more comparable, we drop the 160 individuals from our Period 2 data that have more than 25 unique co-offenders. ${ }^{8}$ After dropping these observations, the maximum number of unique co-offenders in the Period 2 data is 23.

Descriptive statistics are reported in Table 1 . The Period 1 data set includes 15,205 cooffenders who are suspected of committing (on average) 5.92 crimes each. The Period 1 network data includes 1,187 separate networks. ${ }^{9}$ The Period 2 data set includes 15,144 co-offenders who are suspected of committing (on average) 5.92 crimes each. The Period 2 network data includes 1,185 unique networks. Our data also include 3,882 individuals who are members of a network with four or more persons in both periods.

[Insert Table 1 here]

\footnotetext{
${ }^{8}$ For reasons of confidentiality, we are not allowed to disclose more detailed information concerning small groups of individuals.

${ }^{9}$ We define a "separate" network or a network component as a connected network, which needs to satisfy the two following conditions. First, two agents in a network are either directly linked, or are indirectly linked through a sequence of agents (this is the requirement of connectedness). Second, two agents in different network components cannot be connected through any such sequence (this is the requirement of maximality).
} 
We also keep track of how many crimes each pair of co-offenders is suspected of committing together in each period. If two people are suspected of committing three crimes together within one period, then they may have committed three different crimes on one occasion or they may have committed one crime each year for three years in a row. We treat both cases equivalently. We use this information to weight links when weighting is appropriate.

Co-offenders in our data set commit 284 different types of co-offenses between the years 2000 and 2005. The 15 most frequent co-offenses in our data account for half of all of the offenses in our suspects data. These 15 types of crime are (in order of frequency, highest to lowest); (1) possession of narcotics, (2) car theft, (3) theft from a car, trailer, or caravan, (4) theft from commercial establishment, without breaking in, shoplifting, (5) theft, without breaking in, not shoplifting, (6) trespassing; breaking and entering, (7) transfer and/or sale of narcotics, (8) narcotics use, (9) rioting and/or ignoring instructions of public safety officers, (10) accounting fraud, (11) assault, outdoors, against male $>=15$ years old, suspect and offer have no known relationship, (12) receiving and selling stolen goods, not habitual, (13) fraud, other, (14) unlawful threat, against male $>=18$ years old, and (15) theft, other. ${ }^{10}$

\section{Network Level Statistics}

Our data are comprised of $N=\{1,2, \ldots, n\}$ crime suspects; $n$ in Period 1 equals 15,205, while $n$ in Period 2 equals 15,144. The relationship between any two suspects is defined by $g_{i j} \in\{0,1\}$, where $g_{i j}=1$ for when $i$ and $j$ are suspected of committing a crime together, i.e. they are co-

\footnotetext{
${ }^{10}$ Co-offenses are fairly representative for crime in general. Using individual level conviction data for Sweden, Hjalmarsson et al. (2012) report that the five most common violent crimes are (in order of frequency); assault, molestation, unlawful threat, aggravated assault and aggravated unlawful threat. The five most common property crimes are petty theft (mainly shoplifting), theft, vandalism, larceny and fraud. The five most common "other" crimes are dangerous driving, driving without a license, unlawful driving, smuggling and minor narcotic offenses. Some of these crime types, however, are not found in our co-offense data, since they are by definition not "network" crimes (e.g. dangerous driving, driving without a license, and unlawful driving).
} 
offenders, and $g_{i j}=0$ otherwise. A crime network, $g$, is a collection of suspects and the links between them.

The set of suspect $i$ 's co-offenders is given by $\mathcal{N}_{i}(g)=\left\{j \in N: g_{i j}=1\right\}$. The degree of individual $i$ is defined as the number of co-offenders that $i$ is directly linked to, $\gamma_{i}(g)=$ $\left|\mathcal{N}_{i}(g)\right|$. The average degree of network $g$ is given by the sum of the degrees of each suspect in the network divided by the total number of suspects, $\gamma(g)=\sum_{i=1}^{n} \gamma_{i}(g) / n$. This, in turn, can be averaged across all of the networks in our data set, $\Gamma(g)$.

We say that a path exists between suspect $i$ and $j$ if $g_{i j}=1$ or if there exists a series of links that connect $i$ to $j$, for example, through a series of co-co-offenders, co-co-co-offenders, etc., such that $g_{i j 1}=g_{j 1 j 2}=\ldots=g_{j x j}=1$. The distance between two suspects in a connected network is define as the length of the shortest path between them, $\delta_{i j}(g)$. The average distance in a connected network is given by $\delta(g)=\sum_{i=1}^{n} \sum_{j=1}^{n} \delta_{i j}(g) / n(n-1)$, which, in turn, can be averaged over all of the networks in our data in order to produce the average distance in our complete network data set, $\Delta(g)$.

The clustering coefficient of a network measures the degree of overlap between cooffenders. It answers the following type of question: To what extent do my co-offenders also cooffend with each other even when I am not around? The level of clustering in the neighborhood of individual $i$ is given by $c_{i}(g)=\sum_{j=1}^{n} \sum_{k=1}^{n} g_{j k} / \gamma_{i}\left(\gamma_{i}-1\right)$ for all $i$ with $\gamma_{i} \geq 2$. The clustering coefficient of a network $g$ is defined by the weighted average of these $c_{i}(g)$, such that $c(g)=\sum_{i=1}^{n}\left[\gamma_{i}\left(\gamma_{i}-1\right) c_{i}(g) / \sum_{j=1}^{n} \gamma_{j}\left(\gamma_{j}-1\right)\right]$ for all $i$ with $\gamma_{i} \geq 2$ and $j$ with $\gamma_{j} \geq 2$.

Network level descriptive statistics for Period 1 and Period 2 are presented in Table 2. The average degree, $\Gamma(g)$, in the Period 1 network data is 2.88 and the average degree in the Period 2 data is 2.99. As stated above, the Period 1 data is comprised of 1,187 unique networks 
and there are 1,185 networks in the Period 2 data. A giant component (network) ${ }^{11}$ is observed in each period. These giant components include $51 \%$ and $50 \%$ of all co-offenders, respectively. The average distance, $\Delta(g)$, between any two co-offenders in the giant component is 16.25 in Period 1 and 17.00 in Period 2. The clustering coefficient, $c(g)$, in the first and second periods are 0.52 and 0.55 , respectively.

\section{[Insert Table 2 here]}

To get a better sense of what these statistics mean, we can compare our crime network statistics with those from co-authorship networks in economics (Goyal et al. 2006). Both types of networks display giant components of comparable sizes. ${ }^{12}$ But the average distance between any two co-offenders is nearly twice as large as that between any two co-authors. Also, we see very high clustering coefficients in the crime network data. My co-offenders tend to also co-offend with each other, while my co-authors may not necessarily write together. Thus, activity within crime networks appears to be much more concentrated to one's immediate neighborhood with larger distances between these neighborhoods. One potential explanation of the architectural differences between these two types of networks (co-authors vs. co-offenders) is that clandestine networks may act this way in order to minimize the risk of detection.

In Figures 1 and 2, we compare the degree distributions of our Period 1 and Period 2 data with randomly generated networks. ${ }^{13}$ We see that the degree distribution is skewed somewhat to the left of the random distribution. Thus, the average degrees in the Period 1 and Period 2 data are somewhat lower than those of their corresponding random graphs. This, in turn, implies that

\footnotetext{
${ }^{11}$ which is simply the largest "separate" network (i.e. the one that has the higher number of co-offenders) among all networks.

${ }^{12}$ During the 1990's the co-authorship network had a giant component that included 41 percent of all authors.

${ }^{13}$ The two random graphs were created with the same number of vertices and edges as found in our raw data. Then singletons, pairs, and triplets were removed in the same manner as when we created our Period 1 and Period 2 data.
} 
links may not be formed at random and that criminal offenders may err on the side of caution when forming new links.

\section{[Insert Figures 1 and 2 here]}

We can explore potential non-randomness in link formation in a logistic model using the observable characteristics described in Table 1 as predictors of links. ${ }^{14}$ We find that women and immigrants form more links than one would expect if links were simply formed at random. We also observe a strong tendency towards homophily. When forming new links, males have a 1.33 higher odds of linking with another male as opposed to forming a new link with a female. The odds of linking to someone born in the same country is 2.14 . We also find that people sort along income, education, employment, family status, and age. Individuals whose age differ by at most +/- 2 year (for example) have a 3.33 higher odds of forming a link than what is predicted by a model with random link formation. People also have a strong tendency to form links with others residing in the same county.

\subsection{Placing Members of the Giant Component into Smaller Communities}

In each period, we observe a giant component that is comprised of roughly half of all cooffenders. These giant components include over 7,500 individuals and exhibits and average path length of more than 16 . This does not map well into our beliefs that the most relevant social interactions and peer effects in co-offending behavior are those which occur within closer communities. We, therefore, partition the nodes in the giant component into a number of smaller

\footnotetext{
${ }^{14}$ We estimate this model using the ergm package in $\mathbf{R}$ (Hunter et al. 2008). Our model is one with dyadic independence. Hence, we avoid the well known problem of model degeneracy. The results are reported in Table 4 as part of our sensitivity analysis in Section 6.2.1.
} 
communities (subgraphs). ${ }^{15}$ We do this using the fastgreedy.community function in the igraph package in $\boldsymbol{R}$ (Clauset et al., 2004). This algorithm finds community structures by joining connected nodes into a dendogram in order to maximize the modularity of each community structure. A high modularity occurs when there are many edges within communities and few between them.

Note that we only apply this algorithm to the giant component. This algorithm breaks the Period 1 giant component into 103 separate communities, ranging in size from 6 to 500 cooffenders. Thus, the number of Period 1 networks we study in the remainder of this paper increases from 1,187 to 1,289 networks. Applying the algorithm to the Period 2 giant component produces 94 new communities, ranging in size from 8 to 404 individuals. This raises the total number of Period 2 networks from 1,185 to $1,278 .^{16}$

\section{Theoretical Framework}

We would now like to present a theoretical model that explains how peer effects operate in criminal networks and how the key player can be calculated. Following Calvó-Armengol and Zenou (2004) and Ballester et al. (2006, 2010), we present a Beckarian-style rational choice model of crime (Becker, 1968) that is extended to include both local aggregate peer effects (strategic complementarities) and contextual effects. The key player policy is then derived from this model.

\footnotetext{
${ }^{15}$ Also, the spectral radius of the adjacency matrix of the giant component is quite large. This makes it unlikely that the equilibrium condition outlined in Proposition 1 (below) will hold for this group of co-offenders. Instead of dropping these observations from the analysis, we break the giant component into smaller communities. See Section 13.2 in Jackson (2008) for a brief discussion concerning methods of identifying community structures in network graphs.

${ }_{16}$ In Section 6.2.4, we present a robustness check for our estimated peer effects which leaves the giant component intact, and another which uses an alternative algorithm to identify community structure.
} 


\subsection{A Model of Peer Effects in Co-offending Networks}

A co-offending network, $g$, is a collection of $N=\{1,2, \ldots, n\}$ crime suspects and the links between them. The link between any two suspects is defined by $g_{i j} \in\{0,1\}$, where $g_{i j}=1$ when $i$ and $j$ are suspected of committing a crime together, i.e. they are co-offenders, and $g_{i j}=0$ otherwise.

Each agent chooses how many crimes to commit, $y_{i} \geq 0$, in order to maximize his or her own utility, $u_{i}(\boldsymbol{y}, \boldsymbol{G})$, which depends on (among other things) the crime profile of all agents in the network, $\boldsymbol{y}=\left(y_{1}, \ldots, y_{n}\right)^{\prime}$, and the adjacency matrix $\boldsymbol{G}$, which describes the fixed architecture of the network. Agent $i$ 's utility function can be written as follows:

$$
u_{i}(\boldsymbol{y}, \boldsymbol{G})=\underbrace{\left(a_{i}+\eta+\theta+\epsilon_{i}\right) y_{i}}_{\text {proceeds }}-\underbrace{\frac{1}{2} y_{i}^{2}}_{\begin{array}{c}
\text { effort } \\
\text { cost }
\end{array}}-\underbrace{p f y_{i}}_{\begin{array}{c}
\text { cost if } \\
\text { caught }
\end{array}}+\underbrace{\phi \sum_{j=1}^{n} g_{i j} y_{i} y_{j}}_{\begin{array}{c}
\text { eeer } \\
\text { effects }
\end{array}} .
$$

Agent $i$ 's utility is a positive function of the proceeds from crime, $\left(a_{i}+\eta+\theta+\epsilon_{i}\right) y_{i}$, which are increasing in own effort, $y_{i}$. Involvement in crime has an effort cost, an opportunity cost, and a social or moral cost. These costs, which are incurred with certainty, are captured by the quadratic loss term, $-\frac{1}{2} y_{i}^{2}$. With probability $p$ an agent is caught and punished with a fine $f$ resulting in the expected utility loss $-p f y_{i}$. Importantly, an agent's utility from crime is increasing in the crime committed by his peers, $y_{j}$. In our application, "peers" are defined as co-offenders with whom you commit crimes together with, i.e. $g_{i j}=1$. Peer effects are modeled as strategic complementarities with $\phi \geq 0$.

In our data, we define the crime effort of individual $i, y_{i}$, as the total number of crimes individual $i$ has committed during a given period, which includes both solo offenses and cooffenses. The link between individuals $i$ and $j, g_{i j}=1$, is defined whenever $i$ and $j$ are suspected of committing a crime together. As stated in Section 2, individuals who are involved in co- 
offending behavior commit on average two solo offenses for every co-offense. Thus, peer effects in our model imply that if individual $j$ has been suspected of committing a crime with individual $i$, then even when individual $i$ commits a crime by herself or with a third person, she is still influenced by individual $j$. In fact, the number of crimes she will commit, $y_{i}$, will depend positively on the total number of crimes her peers (co-offenders) have committed, since they have a positive impact on the marginal utility of crime effort of individual $i$.

The proceeds from crime depend not only on one's own effort, $y_{i}$, but also on one's criminal ability, $a_{i}$. This productive capacity is allowed to differ across agents and is modeled as a function of the agent's own observable characteristics, $\boldsymbol{x}_{i}^{\prime}$, such as gender, age, and education. An agent's effective criminal ability is also affected by the average observable characteristics of the agent's co-offenders, $\frac{1}{\bar{g}_{i}} \sum_{j=1}^{n} g_{i j} x_{j}^{\prime}$. Thus,

$$
a_{i}=\boldsymbol{x}_{i}^{\prime} \boldsymbol{\beta}_{1}+\frac{1}{\bar{g}_{i}} \sum_{j=1}^{n} g_{i j} \boldsymbol{x}_{j}^{\prime} \boldsymbol{\beta}_{2}
$$

where $\bar{g}_{i}$ is the number of co-offenders of agent $i$. The effects of observable individual heterogeneity are given by $\boldsymbol{\beta}_{1}$ and the contextual effects are given by $\boldsymbol{\beta}_{2}$. As Manski (1993, p. 532) put it: "the propensity of an individual to behave in some way varies with the exogenous characteristics of the group", which are the contextual effects. This variation is equal here to $\boldsymbol{\beta}_{2}$.

Proceeds from crime are also influenced by unobservable individual characteristics and idiosyncratic shocks, $\epsilon_{i}$. In our theoretical framework, we assume that agents know $\epsilon_{i}$ when making their crime effort decision. In our empirical framework, however, we must treat these factors as unobservable to the econometrician. Last of all, we allow local conditions and opportunities to affect the proceeds from crime, which is represented by the network fixed effect, 
$\eta$, and the county fixed effect, $\theta \cdot{ }^{17}$ We assume that the probability of getting caught, $p$, and the fine that one pays, $f$, are the same for all members of the network living in the same county. We can, therefore, subtract the financial cost of getting caught from the network and county fixed effects and re-write the utility function (1) as

$$
u_{i}(\boldsymbol{y}, \boldsymbol{G})=\underbrace{\left(a_{i}+\bar{\eta}+\bar{\theta}+\epsilon_{i}\right) y_{i}}_{\text {net proceeds }}-\underbrace{\frac{1}{2} y_{i}^{2}}_{\begin{array}{c}
\text { efort } \\
\text { cost }
\end{array}}+\underbrace{\phi \sum_{j=1}^{n} g_{i j} y_{i} y_{j}}_{\begin{array}{c}
\text { peer } \\
\text { effects }
\end{array}},
$$

where $\bar{\eta}+\bar{\theta}=\eta+\theta-p f$. This specification allows for both network-specific probabilities (since some networks may be more efficient at evading detection than others) and county-specific probabilities (since some police forces may be more effective than others, or since the probability of detection may differ between urban and rural settings).

\subsection{Model Equilibrium}

Before characterizing the Nash equilibrium of our crime effort game, we would first like to present the definition of Bonacich network centrality (Katz 1953, Bonacich 1987). Recall that each of our networks, $g$, has an associated adjacency matrix, $\boldsymbol{G}$, that keeps track of all of the links between agents $i$ and $j, g_{i j}$. The matrix $\boldsymbol{G}^{k}$ can be obtained by multiplying $\boldsymbol{G}$ by $\boldsymbol{G} k$ times. The $i j^{\text {th }}$ element in $\boldsymbol{G}^{k}$ keeps track of the number of paths between agent $i$ and agent $j$ of length $k$.

Definition 1 (Katz 1953, Bonacich 1987): Given a vector $\boldsymbol{u} \in \mathbb{R}_{+}^{n}$, and a small enough scalar $\phi \geq 0$, the vector of Bonacich centralities of parameter $\phi$ in network $g$ is defined as:

$$
\boldsymbol{b}_{\boldsymbol{u}}(g, \phi)=(\boldsymbol{I}-\phi \boldsymbol{G})^{-1} \boldsymbol{u}=\sum_{k=0}^{\infty} \phi^{k} \boldsymbol{G}^{k} \boldsymbol{u}
$$

\footnotetext{
${ }^{17}$ The Swedish police force is organized at the county level. There are 21 counties in Sweden. Counties also capture urban versus rural environments.
} 
The Bonacich centrality of agent $i$ is constructed as the sum of all paths between agent $i$ and all $j \in\{1, \ldots, n\}$ of length 0 to $k$. Each path of length $k$ is weighted by $\phi^{k}$. This number is then multiplied by $u_{i}$

With this definition in hand, we now turn to the Nash equilibrium of our crime effort game. In equilibrium, agents simultaneously choose how many crimes to commit, $y_{i} \geq 0$, in order to maximize their own utility (3). Agents take $\boldsymbol{y}$ and $\boldsymbol{G}$ into account when making this decision. The best-reply function for each agent $i=\{1, \ldots, n\}$ is

$$
y_{i}=\phi \sum_{j=1}^{n} g_{i j} y_{j}+a_{i}+\bar{\eta}+\bar{\theta}+\epsilon_{i}
$$

Where $a_{i}$ is given by (2). Now let $\boldsymbol{\alpha}$ be a non-negative vector containing the values of $a_{i}+\bar{\eta}+$ $\bar{\theta}+\epsilon_{i}$ for each $i$, i.e. $\alpha_{i}=a_{i}+\bar{\eta}+\bar{\theta}+\epsilon_{i}$, and denote the spectral radius of $\boldsymbol{G}$ by $\mu(\boldsymbol{G})$.

Proposition 1 If $\phi \mu(\boldsymbol{G})<1$, the crime effort game with payoffs (3) has a unique Nash equilibrium in pure strategies given by

$$
\boldsymbol{y}^{*} \equiv \boldsymbol{y}^{*}(g)=\boldsymbol{b}_{\boldsymbol{\alpha}}(g, \phi)=(\boldsymbol{I}-\phi \boldsymbol{G})^{-1} \boldsymbol{\alpha}=\sum_{k=0}^{\infty} \phi^{k} \boldsymbol{G}^{k} \boldsymbol{\alpha} .
$$

See Theorem 1 in Ballester et al. (2006) for a proof of Proposition 1.

Proposition 1 tells us that Bonacich is the correct measure of centrality to use when utility functions are linear quadratic. Both concepts (Nash equilibrium and Bonacich centrality) appreciate the notion that individual behavior is affected not only by the behavior of those we are directly connected to, but also by those who we are indirectly connected to. The condition stating that $\phi \mu(\boldsymbol{G})$ must be less than 1 implies that local complementarities must be small enough relative to own concavity, which rules out multiple equilibria and prevents corner solutions 
(Ballester et al. 2006). This condition also guarantees that $(\boldsymbol{I}-\boldsymbol{\phi} \boldsymbol{G})$ is invertible and that its series expansion is well defined.

Using (5) to replace $y_{j}$ in (3) gives us the equilibrium utility payoff, $\frac{1}{2} y_{i}^{* 2}$. Proposition 1 tells us that this is equal to one-half times the square of an agent's Bonacich centrality, $\frac{1}{2}\left[b_{\alpha_{i}}(g, \phi)\right]^{2}$. That is,

$$
u_{i}^{*}\left(\boldsymbol{y}^{*}, \boldsymbol{G}\right)=\alpha_{i} y_{i}^{*}-\frac{1}{2} y_{i}^{* 2}+\phi \sum_{j=1}^{n} g_{i j} y_{i}^{*} y_{j}=\frac{1}{2} y_{i}^{* 2}=\frac{1}{2}\left[b_{\alpha_{i}}(g, \phi)\right]^{2} .
$$

\subsection{The Key Player Policy}

Following Ballester et al. (2006, 2010) and Ballester and Zenou (2014), we define the "key player" as being the individual who when removed from the network leads to the largest reduction in aggregate crime. In the presence of peer effects and incomplete network structures, the key player is not always the same as the most active criminal (Liu et al. 2012). An active, but relatively isolated, individual may not have much sway over the behavior of others in the network. The key player may be an active individual, but more importantly his/her central position in the network allows him/her to directly influence the behavior of many others. The key player also acts as a conduit of indirect influence that flows through him and affects the behavior of many others in the network.

More formally, let $Y^{*}(g)=\sum_{i=1}^{n} y_{i}^{*}(g)$ be the aggregate equilibrium crime level in network $g$ and let $g^{[-i]}$ be the network after removing only agent $i$. The planner's problem is

$$
\min _{\{i\}}\left\{Y^{*}\left(g^{[-i]}\right) \mid i=1, \ldots, n\right\} \text {. }
$$

To solve this problem, and to find the key player in our model, we need to make two assumptions. First, we assume that the architecture of the network (represented by the adjacency matrix $\boldsymbol{G}$ ) is fixed. Agents are not allowed to form new links after agent $i$ is removed. Second, we 
assume that the $a_{i}$ in (2) do not depend on $\boldsymbol{G}$. Given these assumptions, the key player can be found after calculating Ballester and Zenou's (2013) measure of network intercentrality, $d_{i}(g, \phi)$

Definition 2 For all networks $g$ and for all $i$, the intercentrality measure of agent $i$ is:

$$
\begin{aligned}
& d_{i}(g, \phi)=B(g, \phi)-B\left(g^{[-i]}, \phi\right) \\
& =\boldsymbol{l}_{n}^{\prime} \boldsymbol{M} \boldsymbol{\alpha}-\boldsymbol{l}_{n}^{\prime} \boldsymbol{M} \boldsymbol{\alpha}^{[i]}+\boldsymbol{l}_{n}^{\prime} \boldsymbol{M}^{[i]} \boldsymbol{\alpha}^{[i]} \\
& =B(g, \phi)-B\left(g^{[i]}, \phi\right)+\frac{b_{\alpha[i], i}(g, \phi) \sum_{j=1}^{n} m_{j i}(g, \phi)}{m_{i i}(g, \phi)}
\end{aligned}
$$

$B(g, \phi)=\sum_{i=1}^{n} b_{\alpha_{i}}(g, \phi)$ is the total Bonacich centrality in network $g . B\left(g^{[-i]}, \phi\right)$ is the total centrality in $g^{[-i]} . B(g, \phi)=\boldsymbol{l}_{n}^{\prime} \boldsymbol{M} \boldsymbol{\alpha}$ where $\boldsymbol{l}_{n}^{\prime}$ is a vector of ones, $\boldsymbol{M}=(\boldsymbol{I}-\phi \boldsymbol{G})^{-1}$, and $\boldsymbol{\alpha}$ is (as defined above) a non-negative vector containing the values of $a_{i}+\bar{\eta}+\bar{\theta}+\epsilon_{i}$ for each $i$. Let $\boldsymbol{\alpha}^{[-i]}$ be a $(n-1) \times 1$ matrix in which $\alpha_{i}$ has been removed. Then, define $\boldsymbol{\alpha}^{[i]}$ to be a $(n \times 1)$ column vector where all entries but $i$ are defined as $\boldsymbol{\alpha}^{[-i]}$ while entry $i$ contains the initial $\alpha_{i} . \boldsymbol{M}^{[i]}$ is an $(n \times n)$ matrix such that each element is $m_{j k}^{[i]}=\frac{m_{j i} m_{i k}}{m_{i i}} . B\left(g^{[i]}, \phi\right)=\boldsymbol{l}_{n}^{\prime} \boldsymbol{M} \boldsymbol{\alpha}^{[i]}$ and $\frac{b_{\alpha[i], i}(g, \phi) \sum_{j=1}^{n} m_{j i}(g, \phi)}{m_{i i}(g, \phi)}=\boldsymbol{l}_{n}^{\prime} \boldsymbol{M}^{[i]} \boldsymbol{\alpha}^{[i]}$.

The intercentrality measure, $d_{i}(g, \phi)$, illustrates the different mechanisms that are at work and that affect the total amount of crime generated in our model after removing one individual from the network. First, there is a direct effect of removing the agent and his or her own crime. Second, as $\boldsymbol{\alpha}$ changes to $\boldsymbol{\alpha}^{[i]}$, the contextual effects faced by those remaining in the network change (holding $g$ constant). Third, the network architecture changes from $g$ to $g^{[-i]}$ leading to a network effect on behavior. 
Proposition 2 An agent $i^{*}$ in network $g$ is the key player that solves (8) if and only if $i^{*}$ is the agent with the highest intercentrality measure, $d_{i}(g, \phi)$.

See Theorem 3 in Ballester et al. (2006) for a proof of Proposition 2.

\section{Estimating Peer Effects in Co-offending Networks}

\subsection{The Econometric Model}

In order to implement the key player policy, we first need an estimate of peer effects in criminal networks, $\hat{\phi}$, and estimates of $\widehat{\boldsymbol{\alpha}}$. Our data are comprised of $\bar{r}$ networks with $n_{r}$ individuals in each network, $g_{r}$. The econometric model corresponding to the best-reply function (5) can be written as

$$
y_{i, r}=\phi \sum_{j=1}^{n_{r}} g_{i j, r} y_{j, r}+\boldsymbol{x}_{i, r}^{\prime} \boldsymbol{\beta}_{1}+\frac{1}{\bar{g}_{i, r}} \sum_{j=1}^{n_{r}} g_{i j, r} \boldsymbol{x}_{j, r}^{\prime} \boldsymbol{\beta}_{2}+\eta_{r}+\theta+\varepsilon_{i, r}
$$

where $y_{i, r}$, is the best reply for individual $i$ in network, $g_{r} \cdot{ }^{18}$

The number of crimes that agent $i$ is suspected of committing, $y_{i, r}$, is determined by his or her own characteristics (age, gender, education, etc.), $\boldsymbol{x}_{i, r}^{\prime}$, and the average characteristics of his or her peers, $\frac{1}{\bar{g}_{i, r}} \sum_{j=1}^{n_{r}} g_{i j, r} \boldsymbol{x}_{j, r}^{\prime}$, where $\bar{g}_{i, r}$ counts the number of individuals that agent $i$ is directly linked to. Individuals are also influenced by the aggregate activity level of their peers, $\sum_{j=1}^{n_{r}} g_{i j, r} y_{j, r}$. This is the endogenous peer effect, $\phi$, that we want to estimate. The terms $\eta_{r}$ and $\theta$ are network and county fixed-effects, respectively; reflecting local conditions (e.g. criminal opportunities, policing polices, etc.) and individual sorting into networks. These are the correlated effects defined by Manski (1993, p. 533) as follows: "Individuals in the same group

\footnotetext{
${ }^{18}$ To simplify the notation, we suppress county subscripts.
} 
tend to behave similarly because they have similar individual characteristics or face similar institutional environments." Lastly, $\varepsilon_{i, r}$ is a regression error term representing both individual unobservable heterogeneity and idiosyncratic shocks.

Equation (10) can be re-written in matrix form as

$$
\boldsymbol{y}_{r}=\phi \boldsymbol{G}_{r} \boldsymbol{y}_{r}+\boldsymbol{X}_{r} \boldsymbol{\beta}_{1}+\boldsymbol{G}_{r}^{*} \boldsymbol{X}_{r} \boldsymbol{\beta}_{2}+\eta_{r} \boldsymbol{l}_{n_{r}}+\boldsymbol{\theta}+\boldsymbol{\varepsilon}_{r}
$$

where $\boldsymbol{G}_{r}$ is the adjacency matrix of network $r, \boldsymbol{G}_{r}^{*}$ is the row-normalized adjacency matrix, and $\boldsymbol{l}_{n_{r}}$ is a vector of ones. The model for our entire sample of $\bar{r}$ networks is

$$
\boldsymbol{y}=\phi \boldsymbol{G} \boldsymbol{y}+\boldsymbol{X} \boldsymbol{\beta}_{1}+G^{*} X \boldsymbol{\beta}_{2}+\boldsymbol{L} \boldsymbol{\eta}+\boldsymbol{\theta}+\boldsymbol{\varepsilon} .
$$

The data are organized by stacking $\boldsymbol{y}=\left(\boldsymbol{y}_{1}^{\prime}, \ldots, \boldsymbol{y}_{\bar{r}}^{\prime}\right)^{\prime}, \boldsymbol{X}=\left(\boldsymbol{X}_{1}^{\prime}, \ldots, \boldsymbol{X}_{\bar{r}}^{\prime}\right)^{\prime}, \boldsymbol{\eta}=\left(\boldsymbol{\eta}_{1}^{\prime}, \ldots, \boldsymbol{\eta}_{\bar{r}}^{\prime}\right)^{\prime}, \boldsymbol{\theta}=$ $\left(\boldsymbol{\theta}_{1}^{\prime}, \ldots, \boldsymbol{\theta}_{\bar{r}}^{\prime}\right)^{\prime}$, and $\boldsymbol{\varepsilon}=\left(\boldsymbol{\varepsilon}_{1}^{\prime}, \ldots, \boldsymbol{\varepsilon}_{\bar{r}}^{\prime}\right)^{\prime}$, and by constructing a series of block diagonal matrices; $\boldsymbol{G}=\operatorname{diag}\left\{\boldsymbol{G}_{r}\right\}_{r=1}^{\bar{r}}, \boldsymbol{G}^{*}=\operatorname{diag}\left\{\boldsymbol{G}_{r}^{*}\right\}_{r=1}^{\bar{r}}$, and $\boldsymbol{L}=\operatorname{diag}\left\{\boldsymbol{l}_{n_{r}}\right\}_{r=1}^{\bar{r}}$.

When estimating (12) we treat $\boldsymbol{\eta}$ as a vector of unknown parameters. However, when the number of networks, $\bar{r}$, is large, we risk running into the incidental parameter problem. To avoid this, we transform (12) using the deviation from group mean projector $\boldsymbol{J}_{r}=\boldsymbol{I}_{n_{r}}-\frac{1}{n_{r}} \boldsymbol{l}_{n_{r}} \boldsymbol{l}_{n_{r}}^{\prime}$. This transformation is analogous to the within transformation in a fixed-effects panel data model. After pre-multiplying (12) with $\boldsymbol{J}$, and noting that $\boldsymbol{J L}=0$, the transformed model is

$$
J y=\phi J G y+J X \beta_{1}+J G^{*} X \beta_{2}+J \theta+J \omega .
$$

This is the econometric model that we take to the data, where $\phi$ is the peer effect and $\boldsymbol{\beta}_{2}$ are the contextual effects.

\subsection{Identification, Estimation Methods and Weighting}

The main threat to identification of the endogenous peer effect $\phi$ in the transformed model (13) is the reflection problem (Manski 1993). Since individuals are influenced by the members of their 
own group, but not by individuals outside their group, there arises a simultaneity in the behavior of individuals within the group that introduces a perfect collinearity between the endogenous peer effect $\phi$ and the contextual effects $\boldsymbol{\beta}_{2}$. Thus, we cannot disentangle these two effects and we cannot separately identify the endogenous peer effect.

Using the terminology of social networks, the reflection problem arises when networks are complete. That is, when all agents are connected to (and influenced by) all other agents in the network. However, many networks (such as the criminal networks studied in this paper) are not complete; everyone is not connected to everyone else. Bramoullé et al. (2009), Lee et al. (2010), Liu and Lee (2010), Liu et al. (2012), and others have shown us how the architecture of social networks can be used to identify endogenous peer effects. ${ }^{19}$

For the purposes of this paper, there are two somewhat different models of peer effects that are worth distinguishing between. Bramoullé et al. (2009) and others have studied the localaverage endogenous effect, $\phi \boldsymbol{J} \boldsymbol{G}^{*} \boldsymbol{y}$, while we follow the strategy of Liu et al. (2012) and study the local aggregate endogenous effect, $\phi \boldsymbol{J} \boldsymbol{G} \boldsymbol{y}$ (where $\boldsymbol{G}$ and $\boldsymbol{G}^{*}$ are defined as above). Bramoullé et al. (2009) show that peer effects in the local average model can, in fact, be identified when $\boldsymbol{I}$, $\boldsymbol{G}^{*}$, and $\boldsymbol{G}^{* 2}$ are linearly independent, where the matrix $\boldsymbol{G}^{* 2}$ keeps tracks of the friends of your friends. Linear independence implies that $\boldsymbol{G}^{* 2} \boldsymbol{X}, \boldsymbol{G}^{* 3} \boldsymbol{X}$, etc. are not collinear with $\boldsymbol{G}^{*} \boldsymbol{X}$ and can, therefore, be used as valid instruments for $\boldsymbol{G}^{*} \boldsymbol{y}$ given, of course, that $\boldsymbol{X}$ includes relevant predictors of $\boldsymbol{y}$. Liu et al. (2012) show that the same line of argument allows us to use $\boldsymbol{G}^{* 2} \boldsymbol{X}$ as an instrument for $\boldsymbol{G} \boldsymbol{y}$ in order to identify peer effects in the local aggregate model as well. In essence, we are using the fact that a person is not always friends with all of his friends' friends,

\footnotetext{
${ }^{19}$ See Blume et al. (2011) for a recent overview on these and related issues concerning the identification of social interactions.
} 
i.e. the incomplete architecture of social networks provides an exclusion restriction that enables us to identify peer effects net of contextual effects, thereby solving the reflection problem.

Liu et al. (2012) illustrate a number of cases for which this independence assumption does not hold even though the networks are incomplete. They also show that in many of these cases the local aggregate effect can still be identified. They demonstrate how local aggregate effects can be identified using an additional instrument, $\boldsymbol{G} \boldsymbol{L}$, which is simply the number of friends (or co-offenders) and individual has. Here, we are using the fact that a share of one's crime is due to one's unique position in an incomplete network.

With these instruments in hand $\left(\boldsymbol{G}^{* 2} \boldsymbol{X}\right.$ and $\left.\boldsymbol{G} \boldsymbol{L}\right)$, we estimate the local aggregate model (13) using 2SLS (as in Liu and Lee (2010) and Liu et al. (2012)). While both of these instrumental variable strategies solve the issue of simultaneity, it is important to note that these IV strategies do not automatically solve the more traditional endogeneity problem due to unobservable heterogeneity. To solve this important problem, we must also assume that $\boldsymbol{G}$ is exogenous after conditioning on $\boldsymbol{X}, \eta_{r}$, and $\theta$. That is, we must argue that we can account for the endogenous process of network formation by using $\boldsymbol{X}, \eta_{r}$, and $\theta$ as controls and that unobservables cannot explain the remaining networks patterns in $\boldsymbol{G}$ that we use to identify a causal peer effect. In essence, the identity of the "friends of my friends" (in $\boldsymbol{G}^{* 2} \boldsymbol{X}$ ) should be as good as random after conditioning on $\boldsymbol{X}, \eta_{r}$, and $\theta$. Likewise, the variation in the "number of friends" $(\boldsymbol{G} \boldsymbol{L})$ used to identify peer effects should also be as good as random after first conditioning on $\boldsymbol{X}, \eta_{r}$, and $\theta$.

Goldsmith-Pinkham and Imbens (2013) argue that network formation processes characterized by homophily (as ours is) give rise to testable implications that allow us to directly test the conditional exogeneity of $\boldsymbol{G}$. We present such a test in Section 6.2. We cannot reject the 
assumption of conditional exogeneity for $\boldsymbol{G}$. We also present a more traditional over-identifying restriction test as well as an alternative specification that includes lagged crime as a control for unobservable heterogeneity. These tests also speak in favor of the conditional exogeneity of $\boldsymbol{G}$ and, hence, the robustness of our estimated peer effects.

In order to calculate the Bonacich centrality of each agent, and in order to implement the key player policy, we also need estimates of $\widehat{\boldsymbol{\beta}}_{1}$ and $\widehat{\boldsymbol{\beta}}_{2}$. These are used to construct an estimate of $\widehat{\boldsymbol{\alpha}}$. When estimating $\hat{\phi}$ and $\widehat{\boldsymbol{\alpha}}$, the adjacency matrix, $\boldsymbol{G}$, is weighted to take into account the strength of ties between agents. By "strength" we mean the number of times two persons cooffend. We start with an adjacency matrix that is filled with the number of crimes each cooffending pair has committed together, $\boldsymbol{G}^{\text {raw }}$. All elements in each row of $\boldsymbol{G}^{\text {raw }}$ are then divided by the maximum entry in that row. Thus, each entry in $\boldsymbol{G}$ is a number between 0 and 1 , where 1 represents the strongest possible tie between two individuals, i.e. $g_{i j}=1$ when $j$ is the most frequent co-offender of agent $i$. Less frequent co-offenders receive a weight that is greater than 0 , but less than 1. This weighting scheme means that $\boldsymbol{G}$ is no longer symmetric. But Propositions 1 and 2 hold for asymmetric $\boldsymbol{G}$ as well (see Ballester et al. 2006). ${ }^{20}$

\section{Initial Results}

\subsection{Estimated Peer Effects}

Estimation results of equation (13) are reported in Table 3 . We estimate the model separately for each period. The results are very similar across the two periods, which is reassuring and can be viewed as our first robustness check.

\footnotetext{
${ }^{20} \mathrm{We}$ also present unweighted estimates in Section 6.2.
} 
Column (1) of Table 3 reports the raw OLS association between own crime and the aggregate crime of one's peers. The Period 1 association is 0.189 .

\section{[Insert Table 3 here]}

Our Period 1 IV estimate is reported in column (2). The first stage $F$-statistic tell us that $\boldsymbol{G}^{* 2} \boldsymbol{X}$ and $\boldsymbol{G} \boldsymbol{L}$ are, in fact, relevant instruments. We also test for instrument exogeneity using Lee's (1992) over-identifying restrictions test. The $p$-value from this test tells us that we cannot reject the exogeneity of $\boldsymbol{G}^{* 2} \boldsymbol{X}$ and $\boldsymbol{G} \boldsymbol{L}$.

Our 2SLS estimates of the peer effect in Period 1 is $0.167(0.004)$ and in Period 2 it is 0.180 (0.004). Although the Period 2 estimates are somewhat larger, the difference between the raw association and our 2SLS estimates are quite similar across periods. Our estimated peer effects lie within the permissible parameter space as defined in Proposition 1, $\left[0,1 / \mu(\boldsymbol{G}){ }^{21}\right.$

Let us now interpret the estimate of 0.167 using our theoretical model. Consider equation (5), which gives the optimal crime effort of each individual $i$ as a function of his/her peers (i.e. co-offenders). Denote $\alpha_{i} \equiv a_{i}+\bar{\eta}+\bar{\theta}+\epsilon_{i}$ so that we have: $y_{i}=\phi \sum_{j=1}^{n} g_{i j} y_{j}+\alpha_{i}$ and consider a network of two individuals (the dyad). For simplicity and to highlight our result, consider two identical individuals such that $\alpha_{1}=\alpha_{2}=\alpha$. If the two individuals were not linked to each other, $g_{12}=0$, then each individual will commit $y^{*}=\alpha$ crimes. Now, if they are linked to each other, $g_{12}=1$, then, if $\phi<1$, each individual will commit $y^{*}=\frac{\alpha}{1-\phi}$ crimes where $\frac{1}{1-\phi}$ is the social multiplier. Since we found that $\hat{\phi}=0.167$, this means that having only one friend increases my crime from $\alpha$ (when I'm alone) to $1.2 \alpha$ crimes, i.e. crime has increased by 20 percent. Consider the case of four individuals (our smallest network). If there were no links

\footnotetext{
${ }^{21}$ In Period 1, the mean of $\hat{\phi} \mu\left(g_{r}\right)$ across all networks is 0.46 and the standard deviation is 0.24 . In total, 37 Period 1 networks involving 2,147 individuals ( $14 \%$ of the Period 1 sample) have $\hat{\phi} \mu\left(g_{r}\right) \geq 1$. These observations are dropped from our subsequent test of the key player policy.
} 
between them, then each will provide $\alpha$ crimes while, if the network is complete (i.e. fully connected) so that all agents have a link with each other, then, if $\phi<1 / 3$, each of them will provide $\left(\frac{1}{1-3 \phi}\right) \alpha$ crimes, where now the social multiplier is higher and equal to $\frac{1}{1-3 \phi}$. Since $\hat{\phi}=0.167$, the social multiplier is 2 , indicating that, compared to the isolated case, individual crime has increased by 100 percent.

Of course, most networks are not fully connected and will, therefore, have somewhat smaller within network multiplier effects. However, the average network is much larger than 4 persons, so the social multiplier will still be relatively large. For example, in our Period 1 network data, the typical agent has an average of 2.46 weighted links. Thus, the average, within network social multiplier will be equal to $\frac{1}{1-2.46 \phi}=\frac{1}{1-2.46 * 0.167}=1.7$.

So what share of total crime in society can we ascribe to this estimated peer effect? First, we need to make clear that our model makes the very strong assumption that crimes committed by individuals with no co-offenses/offenders have no impact on the criminal behavior of others in society; not on friends, families, co-workers, etc. This strong assumption may bias such a thought experiment downwards. Second, we see in our data that co-offenders account for $74 \%$ of all suspected crimes. Thus, the question we want to ask is: "What share of this $74 \%$ can be accounted for by peer effects?" Using a multiplier of 1.7 , and recalling that $\alpha$ is the amount of crime an individual commits in isolation, we calculate that $30 \%$ of the $74 \%$ of all crime that is committed by co-offenders is due to peer effects, which, in turn, implies that $22 \%$ (i.e., $0.3 * 0.74$ ) of all crime in Sweden is due to peer effects. ${ }^{22}$

$22 \underbrace{\frac{1}{1-2.46 \phi}}_{\begin{array}{c}\text { crime due to crime } \\ \text { peer effecs }\end{array}} \underset{\begin{array}{c}\text { own } \\ \text { crime }\end{array}}{\alpha}=$ total crime committed by co-offenders; 


\subsection{Exogeneity tests and Robustness Checks}

\subsubsection{Conditional Exogeneity}

According to the over identification test in Table 3, we cannot reject that our instruments are conditionally exogenous. However comforting, this may not be perfectly convincing given that both instruments are constructed as functions of $\boldsymbol{G}$. We argue that they use different types of information gleaned from $\boldsymbol{G}$. But nonetheless, they both rely on the assumption that $\boldsymbol{G}$ is conditionally exogenous. Thus, one must still consider the possibility that the associations we measure in peer outcomes are not true peer effects, but rather correlated effects due to the fact that people who chooses to associate with each other may have correlated unobservable characteristics that are not fully captured by network and/or county fixed effects, or by our set of individual- and group-level controls.

Following Goldsmith-Pinkham and Imbens (2013), we further test the conditional exogeneity of $\boldsymbol{G}$ using the following model of crime with endogenous network formation:

$$
\begin{aligned}
& y_{i}=\beta_{0} \sum_{j=1}^{n} g_{i j} y_{j}+\beta_{x} x_{i}+\beta_{j} \frac{1}{\bar{g}_{i}} \sum_{j=1}^{n} g_{i j} x_{j}+\bar{\eta}+\bar{\theta}+\beta_{\xi} \xi_{i}+\omega_{i}, \\
& u_{i j}=\alpha_{0}+\alpha_{x}\left|x_{i}-x_{j}\right|+\alpha_{\xi}\left|\xi_{i}-\xi_{j}\right|+\varepsilon_{i} .
\end{aligned}
$$

Equation (14a) is the best reply function from our model with an additional term, $\xi_{i}$, representing unobservable characteristics. We assume that $\beta_{\xi}>0$, i.e. that crime is increasing in unobservables. Equation (14b) is a simple model of link formation. The utility to agent $i$ of a link with agent $j, u_{i j}$, is a function of the similarity between agents $i$ and $j$ in terms of observable and unobservable characteristics. In accordance with the data, we will assume homophilic behavior (assortative matching), so that $\alpha_{\xi}$ is negative. When $\alpha_{\xi}<0$ and $\beta_{\xi}>0$, then this model

$\frac{1}{1-2.46 * 0.167} \alpha=1.7 \alpha=74 \% ; \alpha=$ own crime $=\frac{74 \%}{1.7}=44 \% ;$ peer effects $=74 \%-44 \%=30 \%$. 
produces a correlation in outcomes among peers due to endogenous link formation based on similarities in unobservables.

Now suppose that we know $\boldsymbol{\alpha}$ and $\boldsymbol{\beta}$ and that link formation does not depend on unobservables (i.e., that conditional exogeneity holds). In this case, we can calculate the probability of $i$ and $j$ linking to each other:

$$
q_{i j}=\operatorname{pr}\left(u_{i j}>0, u_{j i}>0 \mid X\right)=p_{i j} \cdot p_{j i},
$$

where

$$
p_{i j}=\frac{\exp \left(\alpha_{0}+\alpha_{x}\left|x_{i}-x_{j}\right|\right)}{1+\exp \left(\alpha_{0}+\alpha_{x}\left|x_{i}-x_{j}\right|\right)}
$$

We can also calculate the residuals from the outcome equation:

$$
\omega_{i}=y_{i}-\beta_{0} \sum_{j=1}^{n} g_{i j} y_{j}+\beta_{x} x_{i}+\beta_{j} \frac{1}{\bar{g}_{i}} \sum_{j=1}^{n} g_{i j} x_{j}+\bar{\eta}+\bar{\theta}
$$

Under the maintained assumption of exogeneity of $\boldsymbol{G}, q_{i j}$ is orthogonal to $\omega_{i}$.

However, if $\alpha_{\xi}<0$ and $\beta_{\xi}>0$, then the absolute value of the difference in residuals, $\left|\omega_{i}-\omega_{j}\right|$, is increasing in the ex ante probability of a link between $i$ and $j, q_{i j}$. That is, if $i$ and $j$ have a low ex ante probability of being linked together (based on observables), but we still see them linked in the data, then these two agents must be very similar in terms of unobservables. Hence, the difference between their residuals must be small. This is a testable implication of the model with endogenous link formation (Equations 14a and 14b). ${ }^{23}$

To test this, we first estimate a link formation model based on observable characteristics, $\left|x_{i}-x_{j}\right|{ }^{24}$ In Table 4 , we see that link formation is clearly driven by homophilic behavior. Individuals with similar characteristics tend to form links. We then use these estimates to assign

\footnotetext{
${ }^{23}$ See Goldsmith-Pinkham and Imbens (2013) for a more detailed description of this and related tests.

${ }^{24}$ We estimate a logistic model using the observable characteristics described in Table 1 as predictors of links. We estimate this model using the ergm package in $\mathbf{R}$ (Hunter et al. 2008). Our model is one with dyadic independence. Hence, we avoid the well known problem of model degeneracy.
} 
ex ante link probabilities, $q_{i j}$, to each possible link within each network. The estimated OLS association between $q_{i j}$ and $\omega_{i}$ (taken from our 2SLS regression) is zero, $-0.001(0.000)$, as it should be if exogeneity holds.

We then look at only those $i j$ pairs who are actually linked in our data. For these pairs, we create two new variables: $l o w \_q_{i j}$, which we set equal to 1 if the ex ante probability of a match between these two agents is in the lowest quartile of $q_{i j}$ (and 0 otherwise), and low_ $\omega_{i j}$, which we set equal to 1 if $\left|\omega_{i}-\omega_{j}\right|$ is in the lowest quartile of $\left|\omega_{i}-\omega_{j}\right|$ (and 0 otherwise). If $\alpha_{\xi}<0$ and $\beta_{\xi}>0$, then the association between these two new variables should be positive. Instead, the OLS association that we obtain is small and negative, $-0.036(0.005) .{ }^{25}$ Once again, we cannot reject the assumption that $\boldsymbol{G}$ is conditionally exogenous.

\section{[Insert Table 4 here]}

The last strategy that we use to address this issue is to include lagged crime as a proxy for unobservable heterogeneity. In panel B of Table 5, we see that this does lower our estimated peer effect from 0.167 to 0.144 . This difference, however, is not dramatic and this new estimate may suffer from a downward bias (since we are now using the lagged dependent variable as a control). In terms of the quantitative importance of peer effects, this more conservative estimate would lower the overall importance of peer effects from explaining $22 \%$ of aggregate crime to explaining $19 \%$ of aggregate crime.

\section{[Insert Table 5 here]}

\subsubsection{Falsification Tests}

To further judge the suitability of our estimation methods, we present the results from two falsification tests. We begin with a simple placebo test. We generate a random network of links

\footnotetext{
${ }^{25}$ Defining the cutoff in terms of smaller "bins", e.g. quintiles, pushes this number closer to zero and makes it insignificant
} 
(with the same number of nodes and edges as in our real network data) and assign these links to the co-offenders in our data. Co-offenders retain all of their other real world characteristics. We then re-estimate our crime model. The results of this exercise are reported in Panel C of Table 5. What we find is a set of precisely estimated zeros. We also see that our IV estimator no longer has a first stage. We argue that true peer effects flow through the real world network links that we observe in the data. In contrast to this, we see no measurable peer effect when fake links are assigned to individuals at random.

We also run a second, more stringent falsification test. This time we create false links between agents based on their observable characteristics. This means that we are constructing a nonrandom placebo test that includes contextual effects, but excludes true peer effects. The question then is whether or not our identification strategy can distinguish between these two effects?

This nonrandom placebo test, relies on the idea that we can estimate a network formation model and then predict which links are most likely to form. A set of real world network statistics together with the strong degree of homophily observed in our data allow us to do this. Using the model from above (Table 4), we predict the likelihood that any two agents will form a link. Then we replace non-existing links (zeros in $\boldsymbol{G}$ ) with highly likely links, while at the same time excluding all true links from $\boldsymbol{G}$. Thus, we have created a network of false peers that have correlated observable characteristics and (subsequently) correlated outcomes as well. ${ }^{26}$

In Panel D of Table 5, we see that we now estimate a positive OLS association. This raw association (0.028) reflects the contextual effect, which is quite close to the size that we might expect from our baseline estimates (OLS - IV $=0.189-0.167=0.022$ ). Our IV estimate is (once again) a precisely estimated zero (as it should be).

\footnotetext{
${ }^{26}$ This test is similar in spirit to Card and Giuliano's (2013) "fake friends" test.
} 


\subsubsection{Hidden Links}

Another potential threat to our identification strategy is that of hidden links. By this we mean that individuals $i$ and $k$ have co-offended together, but that this co-offense was not recorded by the police. We believe this type of measurement error could be especially important in our application, since we are studying covert activities that the perpetrators are purposefully trying to conceal from the police.

We propose two ways of exploring this type of measurement error. Our first approach is similar in spirit to the nonrandom placebo test discussed above. It also relies on the idea that we can estimate a network formation model and then predict which links are most likely to form. Using this model, we (once again) predict the likelihood that any two agents will form a link. Then we replace non-existing links (zeros in $\boldsymbol{G}$ ) with highly likely links. These highly likely links act as proxies for potentially hidden links.

Using this procedure, we increase the number of links by $20 \%$. We assign each of these new links a weight that is equal to the mean weight observed in the data, 0.88 . We then reestimate our crime model and find that the raw OLS association falls by $28 \%$, which implies that we are adding more noise than new information. In Panel E of Table 5, we also see that our IV estimate decreases by $34 \%$, i.e., by roughly the same amount as the raw OLS association. While this is not direct evidence in favor of our IV exclusion restrictions, the exercise could have spoken clearly against it, which it does not.

Our second experiment adopts a more data drive approach to uncover links that are potentially hidden in our Period 1 data (2000-2002). To do this, we look in our Period 2 data (2003-2005) for individuals that are also in our Period 1 data. Then we search for Period 2 links between people who are not linked in Period 1. The idea here is that we assume that some people (or links) have simply not been discovered yet and that over time they do get discovered. We find 
2,331 such links. We add these links to the Period 1 adjacency matrix $\boldsymbol{G}$ (which increases the total number of links by $11 \%$ ) and then re-estimate our model.

We find that the raw OLS association falls by $14 \%$ (compared to our baseline estimate). Just as in the previous exercise, we appear to be adding more noise than new information. In Panel F of Table 5, we see that our IV estimate falls to 0.13 .

\subsubsection{Further Robustness Checks}

Table 5 also reports the results from several robustness checks. Recall that we chose to break the giant component into smaller communities using a particular algorithm based on community modularity. We did this before estimating our baseline peer effects. In panel $G$, we show estimates of the peer effect leaving the giant component intact. This produces a slightly smaller estimate of the peer effect. In panel $\mathrm{H}$, we use an alternative algorithm that identifies communities by looking at those individuals who are connected to each other by rather short random walks. ${ }^{27}$ In this case, the estimate is nearly the same as our baseline estimate.

In Panel I of Table 5, we present estimates of the peer effect using the unweighted adjacency matrix. This is more out of general interest than anything else, since we believe that the weighted version of this exercise that takes into consideration the strength of ties between individuals is the most appropriate way to address this issue. The estimated peer effect in the unweighted exercise is 0.15 .

\footnotetext{
${ }^{27}$ One disadvantage of this "walk trap" community algorithm is that it leaves several large networks intact and it produces a number of small networks of size 3 .
} 


\subsection{Individual-Level Measures of Network Centrality}

One of the primary purposes of this paper is to test the empirical relevance of the key player policy. We also want to compare its predictive performance when compared to other, more traditional measure of network centrality. We therefore explore four different individual-level measures of network centrality: (i) betweenness centrality, (ii) eigenvector centrality, (iii) Bonacich centrality, and (iv) the key player policy (Ballester et al.'s intercentrality measure). We have already defined (iii) and (iv) in Section 4. Definitions of (i) and (ii) are presented here.

Betweenness centrality, $C_{i}^{B}(g)$, describes how well situated an individual is in his/her network in terms of the number of shortest paths between other agents that run through him/her (Freeman 1977, 1979). Denote the number of shortest paths between agents $j$ and $k$ that agent $i$ lies on as $P_{i}(j k)$ and let $P(j k)$ denote the total number of shortest paths between agents $j$ and $k$. The ratio $P_{i}(j k) / P(j k)$ tells us how important agent $i$ is for connecting agents $j$ and $k$ to each other. Averaging across all possible $j k$ pairs gives us the betweenness centrality measure of agent $i$ : $C_{i}^{B}(g)=\sum_{j \neq k: i \notin\{j, k\}} \frac{P_{i}(j k) / P(j k)}{(n-1)(n-2) / 2}$.

Eigenvector centrality, $C_{i}^{E}(g)$, measures the importance of an agent in a network. (Bonacich 1972). It assigns high centrality scores to agents with a large number of connections to other highly connected agents. The centrality of agent $i$ is proportional to the centrality of $i$ 's neighbors, $\lambda C_{i}^{E}(g)=\sum_{j} g_{i j} C_{j}^{E}(g)$, which can be written in matrix notation as $\lambda C^{E}(g)=$ $g C^{E}(g)$. In general, there will be many eigenvalues, $\lambda$, for which an eigenvector solution exists for this system of equations. However, we are only interested in the eigenvector associated with the largest eigenvalue. As a result, using the Perron-Frobenius theorem, there always exists an associated nonnegative eigenvector, the eigenvector centrality of agent $i, C_{i}^{E}(g)$, which is defined as the $i^{\text {th }}$ entry in the eigenvector associated with the largest eigenvalue, $\hat{\lambda}$. 
Table 6 reports pair wise correlations between these four different measures of network centrality in Period 1 and Period 2. We see that there are strong within period correlations between the eigenvector and betweenness measures, and between the Bonacich and intercentrality measures. However, there is very little correlation between these two different categories of measures. We also see that the correlations across periods are either zero or rather small. The two exceptions to this generalization are the own, cross-period correlations for eigenvector centrality and (to a lesser extent) Bonacich centrality.

[Insert Table 6 here]

\section{The Key Player}

Our Period 1 data include 15,205 individuals involved in 1,289 different networks. Thirty-seven of these networks involving 2,147 individuals (14\% of the sample) are dropped from the following analysis, since they have $\hat{\phi} \mu\left(g_{r}\right) \geq 1{ }^{28}$ Thus, we study 13,057 individuals in 1,251 distinct networks. Figure 3 shows the distribution of these networks by size.

\section{[Insert Figure 3 here]}

In these data, $67 \%$ of all key players are not the most active criminal in their own networks; $34 \%$ do not have the highest eigenvector centrality and $50 \%$ do not have the highest betweenness centrality. ${ }^{29}$ The distribution of these shares across networks of different sizes is shown in Figure 4. As network size increases, it becomes even less likely that the key player is the most active player or is the player with the highest betweenness centrality. The match between the key player and the player with the highest eigenvector centrality, however, does not

\footnotetext{
${ }^{28}$ From proposition 1 we know that if $\phi \mu(\boldsymbol{G}) \geq 1$, then the crime effort game does not have a unique Nash equilibrium in pure strategies. Excluded and included individuals are similar in terms of their observable characteristics.

${ }^{29}$ The key player is uniquely determined in every network. In a few networks, more than one person may have committed the same maximum number of crimes or share the same highest eigenvector centrality or betweenness centrality. In these cases, we pick one of these persons at random. But only after first checking that this randomly chosen individual (among those sharing the highest value) is not the key player.
} 
depend on network size. These results are similar to those of Liu et al. (2012) who also compare the key player policy with other centrality measures but for juvenile delinquents in the United States (using AddHealth data).

\section{[Insert Figure 4 here]}

A simple, multivariate regression describes the average characteristics of the key player as a slightly younger than average male (compared with other offenders) who was born in Sweden. He has less schooling than other offenders, but higher income. He has not necessarily been an active criminal in the past.

\section{Testing the Key Player Model}

What is the predicted reduction in crime achieved after removing the key player? To investigate this, we first calculate the percentage decrease in crime obtained in each network after removing the key player. This is equal to 100 times the intercentrality of the key player in each network divided by the total Bonacich of that network, $\frac{100 * d_{i}\left(g_{r}, \widehat{\phi}\right)_{\max }}{B\left(g_{r}, \widehat{\phi}\right)}$. The percentage reduction in crime can then be regressed on a constant and on a variable for network size. The results from this weighted OLS are:

$$
\frac{100 * d_{i}\left(g_{r}, \widehat{\phi}\right)_{\max }}{B\left(g_{r}, \widehat{\phi}\right)}=\gamma_{1}+\gamma_{2} \text { NetworkSize }{ }_{r}+\varepsilon_{r}=\begin{gathered}
37.64 \\
(0.140)
\end{gathered}-\begin{gathered}
0.16 \\
(0.001)
\end{gathered}
$$

Equation (18) summarizes (and quantifies) two of the main predictions of the key player model. First, the key player model predicts that the population weighted average reduction in crime for the mean network (with size $=62$ ) is equal to $38 \%$. Second, it tells us that this reduction in crime is negatively related to network size. If we look at a network that is twice as large as the 
mean network (i.e., with size $=124$ ), then the predicted $\%$ reduction in crime is equal to $28 \%$. The predicted decrease for our smallest networks (with size $=4$ ) is equal to $47 \%$.

Keep in mind that our model also tells us that the largest reduction possible is achieved by removing the key player. Removing people at random or removing the most active player, the player with the highest betweenness, or the highest eigenvector centrality can only produce smaller reductions in crime. Thus, we should re-estimate (18) in relative terms as well. What we want to know is by how much does the key player policy outperform other reasonable policies?

These results are shown in Table 7. Note that these results apply to the cases when the key player and the other player type are not the same individual. In these cases, the key player policy outperforms the policy of removing one random individual from each network by $14 \%$ (on average). It outperforms the policy of removing the most active person from each network by an average of $13 \%$. Our model predicts that the key player policy will outperform more traditional measures of network centrality such as betweenness and eigenvector centrality by $7 \%$ and $4 \%$, respectively.

\section{[Insert Table 7 here]}

We now want to test these predictions against the true outcome observed in our Period 2 data. We start by calculating the total change in actual crime experienced by each network of individuals. Those who do not show up in our Period 2 data (i.e., those who are not suspected of committing a crime together with a co-offender in Period 2) are assigned zeros in Period 2. We then create dummy variables for different scenarios; key player removed, which is equal to one if the key player is not suspected of co-offending in Period 2 and zero otherwise; type-x player removed, which is equal to one if the type- $x$ player is not suspected of a co-offense in Period 2 and zero otherwise. Type- $x$ is either a random player, the most active player, the player with highest betweenness centrality, or the player with the highest eigenvector centrality. 
We regress the change in aggregate crime measured between Period 1 and Period 2 experienced by each network on the key player removed dummy, the type-x player removed dummy, the interaction between these two dummies (because in some cases both are removed), and on network size (measured in Period 1). The results from this weighted OLS are reported in Table 8. As in Table 7, the sample used in each regression represents those cases for which the key player and the type- $x$ player are not the same person.

Panel B of Table 8 reports the difference between the coefficients on our two dummy variables. This difference tells us that, in the real-world, the key player policy outperforms the random player policy by $6.41 \%$. The key player policy also outperforms the policy of removing the most active player by $2.43 \%$, the policy of removing the player with the highest betweenness centrality by $7.33 \%$, and the policy of removing the player with the highest eigenvector centrality by $17.78 \%$.

\section{[Insert Table 8 here]}

These differences have the same sign as the predicted differences shown in Table 7 and for one of our experiments, that of removing the player with the highest betweennness, the actual difference matches the quantitative predictions of the model. However, our model clearly overstates the relative performance of the key player policy versus the policy of removing the most active criminal and it understates the relative performance of the key player policy in comparison to the removal of the player with the highest eigenvector centrality.

The result concerning the relative performance of the key player policy versus the policy of removing the most active criminal deserves some discussion. In the real world, offenders who are not fully deterred by the loss of the most active criminal in their network most likely form new links in order to achieve their goals. Furthermore, the loss of the most active criminal may open up new opportunities for those not arrested and incarcerated. These two effects are not 
included in our model. We, therefore, think that it is important to stress the fact that the key player policy outperforms the policy of removing the most active criminal by a significant amount despite the fact that offenders may actively re-wire their networks after the loss of an active member and despite a potential short run increase in opportunities. Such effects may explain why our model (with a fixed network structure) over predicts the relative performance of the key player policy relative to the policy of removing the most active criminal.

What exactly does it mean to be "removed" from Period 2 in the above analysis? In short, it means that an agent is not involved in a criminal network in Period 2. But this could be due to several different reasons. The person in question may have died or emigrated from Sweden. They may be in prison. They could be "at large" but have not committed a crime, or could be at large and have committed a crime but did not get caught. They may even be suspected of a crime that they committed on their own and are, hence, removed from their original network, since we are defining links and network membership based on co-offending. The potential existence of solo crimes and unobserved crimes implies that some people may be misclassified as removed when, in fact, they are still active criminals that could potentially be exerting an influence on their former peers.

In panel $\mathrm{C}$ of Table 8 , we look at the relative effect of removing the key player in those cases in which we know that the key player is no longer a part of the active network. To do this, we create an indicator variable for each person indicating whether or not they have died during the relevant time period, emigrated from Sweden, or received a long prison sentence. Since there are few observations in each category we pool them together into one category, which we label dead, emigrated, or in prison. ${ }^{30}$ When we test the relative performance of the key player policy

\footnotetext{
${ }^{30}$ There are very few relevant cases of dead or emigrated, so most of the cases studied using this indicator variable comes from those given long prison sentences in Period 1. We set this at 1800 days, which is the longest sentence
} 
using only the players who are missing from Period 2 for these three specific reasons, we see that the set of estimated effects is quite similar to our estimated baseline effects (albeit much less precisely estimated). ${ }^{31}$

Lastly, we extend the 3-year window of Period 2 to include 6 years. Once again, our worry is that we may be classifying people as "removed" when, in fact, they are still active criminals but have managed to avoid detection. The idea here is that if people are still active in crime they may be able to avoid detection for 3 years but are less likely to avoid detection for 6 years. Importantly, we also look to see if people that we have categorized as being removed from Period 2 have been suspected of any crime at all, including solo crimes committed on their own. Recall that in our baseline experiment an individual was removed if he/she had not co-offended together with another person in a network with four or more co-offenders.

In Panel D of Table 7, we re-run our experiment. Being removed now implies that an individual has not been suspected of any crime (either on his/her own or together with someone else) during the period 2003 to 2008. Basically, these are people who have (as far as we can tell) desisted from crime for good. In this experiment, we see that the key player policy has the same relative effect as before. The desistence of a key player has a much larger crime reducing effect than does the desistance of the random player, the most active player, or any other player type. These findings confirm the saliency of the key player policy.

Thus far, we have shown results for those cases in which the key player and the most active player are not the same person. One can also run this experiment using all observations and all networks, even those in which (for example) the most active player is the same person as the

time we can use, while still have relevant cases for all comparisons, i.e. within each type (key player, most active, random, highest betweenness, and highest eigenvector centrality). Prisoners typically serve 50-66\% of their sentence length (depending on their behavior in prison and the seriousness of the original crime).

31 The exception being the relative performance of the key player policy versus the removal of a random person. Now the superior performance of the key player policy is more evident and in line with the predictions from our model. 
key player. In this scenario, the relative advantage of the key player policy can only go down. At the same time, this should be viewed as the most common sense policy available to the police and should, therefore, be used as a practical benchmark for the overall benefits of implementing the key player policy.

Using all networks, the performance advantage that the key player policy has relative to the removal of the most active player falls from $2.43 \%$ to $1.59 \%$ in our baseline specification. If we use the specification in Panel C the advantage falls from $2.42 \%$ to $2.40 \%$. Lastly, if we use the specification in Panel D the performance advantage of the key player policy falls from $1.95 \%$ to $1.74 \%$. These gains are not trivial, particularly given the relatively low cost of analyzing information that is already available to the police.

Lastly, it is important to note that the relative performance of the key player policy depends in part on the size of the networks studied. For example, in our baseline specification using all individuals, the key player policy outperforms the policy of removing the most active player by $1.59 \%$. This over performance can be more than doubled if we only look at networks that include 7 or more persons. In this case, the key player policy outperforms the removal of the most active criminal by $3.22 \%$. Similarly, our specification concerning the most active player in Panel D of Table 8 rises from an insignificant estimate of $1.95 \%$ to a significant estimate of $4.62 \%$ if we restrict ourselves to looking at networks of size 6 or larger.

\section{Conclusion and discussion}

In this paper, we analyze co-offending networks in Sweden. We first provide credible estimates of peer effects in these networks. We found an estimate of peer effects of 0.167 , which implies a social multiplier of 1.7 . This tells us that $22 \%$ of all crime in society is due to peer effects. We then provide one of the first empirical tests of the key player policy in a real world setting, which 
consists in removing the criminal that reduces total crime the most in the network. By focusing on networks for which the key player has disappeared over time, we show that the theoretical predicted crime reduction is close to what is observed in the real world. We also show that the key player policy clearly outperforms other reasonable police policies such as targeting the most active criminals or criminals who have the highest betweenness or eigenvector centrality in the network.

We believe that our results are complementary to that of Liu et al. (2012) who determine the key player in juvenile friendship networks where crime is self-reported (AddHealth data). Our dataset is much bigger (for example, in Period 1, we have: 1,187 networks, 15,205 criminals and the average network size is 80 ; the corresponding numbers for the AddHealth data are: 150,1297 and 9). Our sampling frame includes $70 \%$ of the Swedish population. Furthermore, criminals are mostly adults and commit more serious crime, which are observed and not self-reported. Despite these differences, some of the results that they report are quite similar to our own: key players are not always the most active criminals and do not always have the highest betweeness centrality in the network. Both studies also show that a key player policy outperforms a random policy by more than $10 \%$ crime reduction.

Our data allow us to evaluate the key player policy even further. One crucial aspect that was not possible to test with the AddHealth data is whether the theoretical prediction in terms of crime reduction after the removal of the key player is close to what is observed in the real-world. Because we have two periods of three years, we were able to test this idea and showed that the theoretical predictions of key player model performed quite well in the real world. We could even pin down the cause of "disappearance" of the key player in the data by distinguishing between “death", "emigration", "prison” or "quitting crime”. Finally, we could also compared our policy 
with other reasonable crime policies and evaluate their impact in the real world. This is also a unique feature of our analysis.

How can we implement the key player policy in the real world? Over the past 10 years, the Swedish police force has received significant increases in resources and yet the effect on crime has been zero or even negative (Örstadius, 2011). The consensus has been that the police did not know how to use this extra money efficiently to reduce crime. Given that our data are coming directly from the police, they could readily adopt a key player policy to reduce crime. For example, in the New York Times article presented in the Introduction, crime in Chicago was sharply reduced when the police focused on the 400 people they have identified as having associations that make them the most likely to be involved in a murder, as a victim or an offender. In our case, the police can identify the 400 people (or even more; if we determine one key player by network, then we will have nearly 1,200 key players) who are the key players and put much of these extra resources on them. They can then monitor them much more closely, offer them incentives to quit crime or leave their gang or network of co-offenders. They could be offered a job or a conditional transfer to enroll in adult education or some other program, or they could be given a first-hand rental contract in a better neighborhood or a new city.

Similar policies (not based on key players but on "prominent" criminals) have been implemented in the US. In Canada, some gang members of criminal networks were persuaded to abandon gang life in return for needed employment training, educational training, and skills training (Tremblay et al., 1996). The advantage with our methodology is that over time the key players will change because the networks change. As a result, every two or three years, the police could determine new key players and target them. Given that most of the criminal networks that we study are quite decentralized and not "mafia" type networks, then even if networks respond endogenously to the extraction of the key player by restructuring or re-grouping in order to 
continue committing crime, the effect on crime reduction will still be large as is shown in our empirical analysis. 


\section{References}

Ballester, Coralio, Antoni Calvó-Armengol, and Yves Zenou (2006) "Who's Who in Networks. Wanted: The Key Player," Econometrica 74(5), 1403-1417.

Ballester, Coralio, Antoni Calvó-Armengol, and Yves Zenou (2010) "Delinquent Networks," Journal of the European Economic Association 8(1), 34-61.

Ballester, Coralio and Yves Zenou (2014) "Key Player Policies When Contextual Effects Matter," Journal of Mathematical Sociology, forthcoming

Bayer, Patrick, Randi Hjalmarsson, and David Pozen (2009) "Building Criminal Capital Behind Bars: Peer Effects in Juvenile Corrections," Quarterly Journal of Economics 124(1), 105-147.

Becker, Gary S. (1968) "Crime and Punishment: An Economic Approach," Journal of Political Economy 76(2), 169-217.

Blume, Lawrence E., William A. Brock, Steven N. Durlauf, and Yannis M. Ioannides (2011) "Identification of Social Interactions," In: Jess benhabib, Alberto Bisin, and Matthew O. Jackson (Eds.), Handbook of Social Economics, Amsterdam: Elsevier Science, pp. 853-964.

Bonacich, Phillip (1972) "Factoring and Weighting Approaches to Clique Identification," Journal of Mathematical Sociology 2(1), 113-120.

Bonacich, Phillip (1987) "Power and Centrality: A Family of Measures," American Journal of Sociology 92(5), 1170-1182.

Borgatti, Stephen P. (2003) "The Key Player Problem," In: Ronald Breiger, Kathleen M. Carley and Philippa Pattison (Eds.), Dynamic Social Network Modeling and Analysis: Workshop Summary and Papers, New York: National Academy of Sciences Press, pp. 241-252.

Borgatti, Stephen P. (2006) "Identifying Sets of Key Players in a Network," Computational, Mathematical and Organizational Theory 12(1), 21-34.

Bramoullé, Yann, Habiba Djebbari, and Bernard Fortin (2009) "Identification of Peer Effects Through Social Networks," Journal of Econometrics 150(1), 41-55.

Calvó-Armengol, Antoni and Yves Zenou (2004) "Social Networks and Crime Decisions. The Role of Social Structure in Facilitating Delinquent Behavior," International Economic Review 45(3), 939-958.

Calvó-Armengol, Antoni, Patacchini, Eleonora and Yves Zenou (2009) "Peer Effects and Social Networks in Education," Review of Economic Studies 76(4), 1239-1267.

Card, David and Laura Giuliano (2013) "Peer Effects and Multiple Equilibria in the Risky Behavior of Friends," Review of Economics and Statistics 95(4), 1130-1149. 
Carrington, Peter J. (2011) "Crime and Social Network Analysis," In: John Scott and Peter J. Carrington (Eds.), Sage Handbook of Social network Analysis, London: Sage Publications, pp. 236-255.

Clauset, Aaron, M. E. J. Newman, and Christopher Moore (2004) "Finding Community Structure in Very Large Networks," http://www.arxiv.org/abs/cond-mat/0408187.

Corno, Lucia (2012) "Peer Effects on Criminal Behavior. Evidence from the Homeless," Unpublished manuscript, University College London.

Damm, Anna P. and Christian Dustmann (2014) "Do Young People Learn Criminal Behavior? Quasi-Experimental Evidence," American Economic Review, forthcoming.

Drago, Francesco and Roberto Galbiati (2012) "Indirect Effects of a Policy Altering Criminal Behavior: Evidence from the Italian Prison Experiment," American Economic Journal: Applied Economics 4(2), 199-218.

Drago, Francesco, Roberto Galbiati, and Pietro Vertova (2009) "The Deterrent Effects of Prison: Evidence from a Natural Experiment," Journal of Political Economy 117(2), 257-280.

Freeman, Linton C. (1977) "Centrality in Social Networks Conceptual Clarification," Social Networks 3(1), 215-239.

Freeman, Linton C. (1979) “A Set of Measures of Centrality Based on Betweenness," Sociometry $40(1), 35-41$

Glaeser, Edward, Bruce Sacerdote, and José A. Scheinkman (1996) "Crime and Social Interactions," Quarterly Journal of Economics 111(2), 507-548.

Goldsmith-Pinkham, Paul and Guido W. Imbens (2013) "Social networks and the Identification of Peer Effects," Journal of Business \& Economic Statistics 31(3), 253-264.

Goyal, Sanjeev, Marco J. van der Leij, and José Luis Moraga-González (2006) "Economics: An Emerging Small World," Journal of Political Economy 114(2), 403-412.

Hjalmarsson, Randi, Helena Holmlund, and Matthew J. Lindquist (2011) "The Effect of Education on Criminal Convictions and Incarceration: Causal Evidence from Micro-data," CEPR Discussion Paper No. 8646.

Hunter, David R., Mark S. Handcock, Carter T. Butts, Steven M. Goodreau, and Martina Morris (2008) "ergm: A Package to Fit, Simulate and Diagnose Exponential-Family Models for Networks," Journal of Statistical Software 24(3), 1-29.

Haynie, Dana L. (2001) "Delinquent Peers Revisited: Does Network Structure Matter?" American Journal of Sociology 106(4), 1013-1057. 
Ioannides, Yannis M. (2013) From Neighborhoods to Nations: The Economics of Social Interactions, Princeton: Princeton University Press.

Jackson, Matthew O. (2008) Social and Economic Networks, Princeton: Princeton University Press.

Jackson, Matthew O. and Yves Zenou (2014) "Games on Networks", In: Peyton Young and Shmuel Zamir (Eds.), Handbook of Game Theory, Vol. 4, Amsterdam: Elsevier Publisher, forthcoming.

Katz, Leo (1953) "A New Status Index Derived from Sociometric Analysis," Psychometrika 18(1), 39-43.

Kling, Jeffrey R., Ludwig, Jens and Lawrence F. Katz (2005) "Neighborhood Effects on Crime for Female and Male Youth: Evidence from a Randomized Housing Voucher Experiment," Quarterly Journal of Economics 120(1), 87-130.

Lee, Lung-Fei (1992) “Amemiya's Generalized Least Squares and Tests of Overidentification in Simultaneous Equation Models with Qualitative or Limited Dependent Variables," Econometric Reviews 11(3), 319-328.

Lee, Lung-Fei, Xiadong Liu, and Xu Lin (2010) "Specification and Estimation of Social Interaction Models with Network Structures,” Econometrics Journal 13(2), 145-176.

Liu, Xiadong and Lung-Fei Lee (2010) "GMM Estimation of Social Interaction Models with Centrality,” Journal of Econometrics 159(1), 99-115.

Liu, Xiaodong, Eleonora Patacchini, Yves Zenou, and Lung-Fei Lee (2012) "Criminal Networks: Who Is the Key Player?" CEPR Discussion Paper No. 8772.

Ludwig, Jens, Duncan, Greg J. and Paul Hirschfield (2001) "Urban Poverty and Juvenile Crime: Evidence from a Randomized Housing-Mobility Experiment," Quarterly Journal of Economics 116(2), 655-679.

Manski, Charles F. (1993) "Identification of Endogenous Effects: The Reflection Problem," Review of Economic Studies 60(3), 531-542.

Mastrobuoni, Giovanni and Eleonora Patacchini (2012) "Organized Crime Networks: an Application of Network Analysis Techniques to the American Mafia," Review of Network Economics 11(3), Article 10, 1-41.

Örstadius, Kristoffer (2011) “Fler Poliser Klarar Upp Färre Brott” Dagens Nyheter, 22 February.

Patacchini, Eleonora and Yves Zenou (2012) "Juvenile Delinquency and Conformism," Journal of Law, Economic, and Organization 28, 1-31. 
Sarnecki, Jerzy (2001) Delinquent Networks: Youth Co-offending in Stockholm, Cambridge University Press.

Stock, James H., Jonathan H. Wright, and Motohiro Yogo (2012) "A Survey of Weak Instruments and Weak Identification in Generalized Method of Moments," Journal of Business and Economic Statistics 20(4), 518-529.

Sutherland, Edwin H. (1947) Principles of Criminology, Fourth edition, Chicago: J.B. Lippincott.

Tayebi, Mohammad A., Laurens Bakker, Uwe Glässer, and Vahid Dabbaghian (2011) "Locating Central Actors in Co-offending Networks," 2011 International Conference on Advances in Social Networks Analysis and Mining, 171-179.

Tremblay, Richard E., Masse, Louise C., Pagani, Linda and Frank Vitaro (1996) "From Childhood Physical Aggression to Adolescent Maladjustment: The Montreal Prevention Experiment," In R.D. Peters and R.J. McMahon (Eds.), Preventing Childhood Disorders, Substance Abuse, and Delinquency, Thousand Oaks, CA: Sage Publications.

Warr, Mark (2002) Companions in Crime: The Social Aspects of Criminal Conduct, Cambridge: Cambridge University Press.

Wasserman, Stanley and Katherine Faust (1994), Social Network Analysis. Methods and Applications, Cambridge: Cambridge University Press. 
Table 1. Individual Level Descriptive Statistics.

\begin{tabular}{lcccc}
\hline \hline & \multicolumn{2}{c}{ Period 1 } & \multicolumn{2}{c}{ Period 2 } \\
& $2000-2002$ & $2003-2005$ \\
& Mean & (s.d.) & Mean & (s.d.) \\
\hline Crime & 5.92 & $(5.53)$ & 5.92 & $(5.62)$ \\
Lagged crime & 4.69 & $(7.04)$ & 3.79 & $(5.36)$ \\
Age & 29.6 & $(11.2)$ & 30.1 & $(11.7)$ \\
Income & 8.35 & $(4.25)$ & 8.14 & $(4.49)$ \\
Months on welfare & 9.03 & $(10.8)$ & 8.50 & $(10.8)$ \\
Years of schooling & 9.86 & $(1.40)$ & 9.84 & $(1.51)$ \\
Missing school info & 0.10 & $(0.30)$ & 0.08 & $(0.27)$ \\
Employed in November & 0.20 & $(0.40)$ & 0.20 & $(0.40)$ \\
Sick days & 40.0 & $(139)$ & 35.2 & $(132)$ \\
Immigrant & 0.24 & $(0.42)$ & 0.26 & $(0.44)$ \\
Male & 0.84 & $(0.37)$ & 0.82 & $(0.38)$ \\
Married or cohabitating & 0.30 & $(0.46)$ & 0.30 & $(0.46)$ \\
Child living at home & 0.53 & $(0.50)$ & 0.54 & $(0.50)$ \\
\hline Nr of individuals & 15,205 & 15,144 \\
Nr of networks & 1,187 & 1,185 \\
\hline \hline
\end{tabular}


Table 2. Network Level Descriptive Statistics (Unweighted).

Period $1 \quad$ Period 2

2000-2002 2003-2006

Number of co-offenders

$15,205 \quad 15,144$

Number of networks

$1,187 \quad 1,185$

Degree:

Average, $\Gamma(g)$

$\begin{array}{ll}2.88 & 2.99\end{array}$

standard deviation

(2.18)

Largest network:

Size

$7,830 \quad 7,592$

Percentage of co-offenders

$51 \% \quad 50 \%$

Size of second largest network:

$49 \quad 45$

Size of smallest networks

4

4

Distance in largest network:
Average, $\Delta(g)$
$16.25 \quad 17.00$
standard deviation
(3.00) (3.40)

Clustering coefficient, $c(g)$

0.52

0.55 
Table 3. OLS and 2SLS Estimates of the Crime Model.

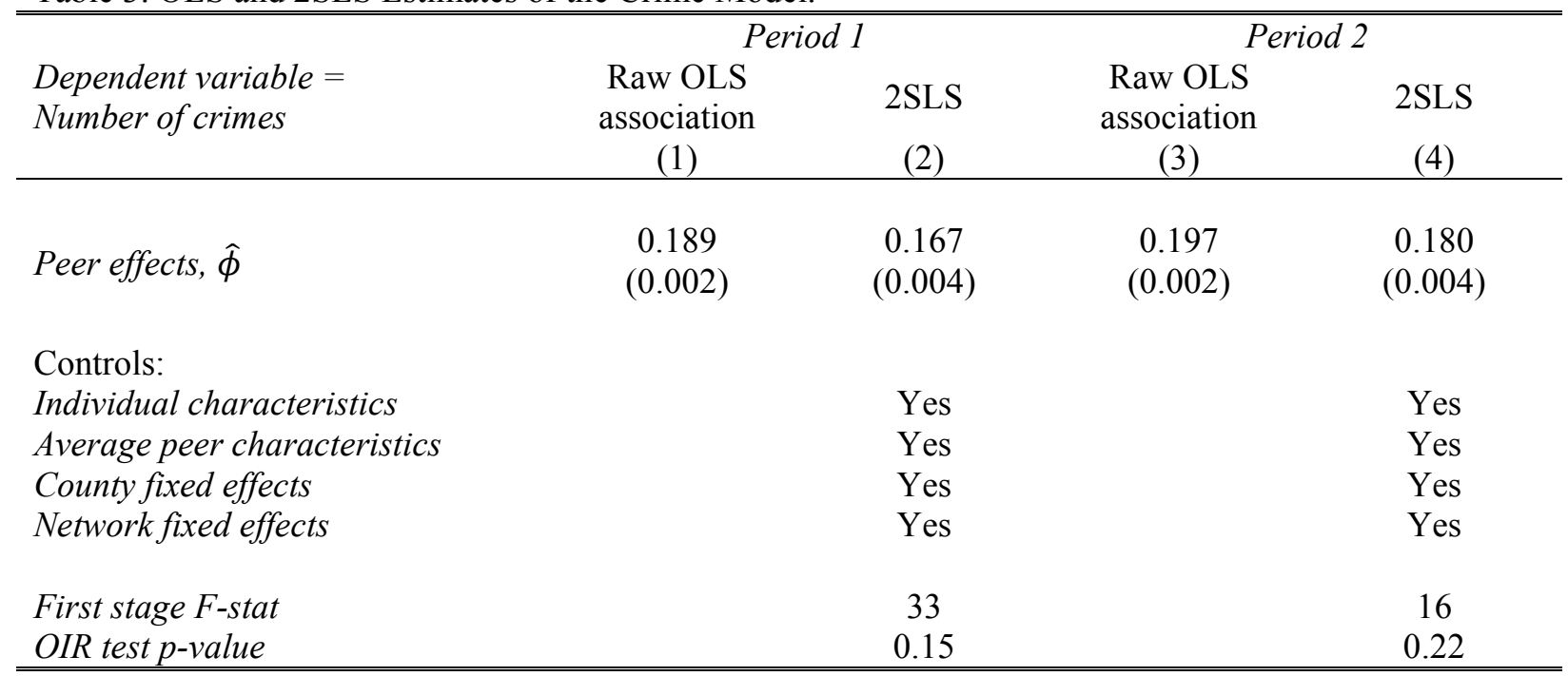

Standard errors in parentheses. In Period 1, the number of observations is 15,205 and the number of networks is 1,289. In Period 2, the number of observations is 15,144 and the number of networks is 1,278 . The individual and average peer characteristics that are included as controls are age, gender, log income, years of schooling (and whether or not this information is missing), immigrant status, marital status, children living at home, employment status (in November), months on welfare, and number of sick days. As discussed in the text, both $\boldsymbol{G}^{* 2} \boldsymbol{X}$ and $\boldsymbol{G} \boldsymbol{L}$ are used as instruments for $\boldsymbol{G} \boldsymbol{y}$ in our 2SLS estimates. The OIR test p-value reported above is computed using Lee's (1992) over-identifying restrictions test. 
Table 4. A Logistic Model of Link Formation.

Dependent variable $=$

$i$ and $j$ are linked $(1 / 0)$

Odds Ratio

Dichotomous control variables:

\begin{tabular}{|c|c|}
\hline$a g e_{i}-a g e_{j} \mid \leq 2$ & $3.33^{* * *}$ \\
\hline gender $_{i}=$ gender $_{j}$ & $1.33^{* * *}$ \\
\hline income $_{\mathrm{i}}=$ income $_{\mathrm{j}} \mid \leq 2 \log$ points & $1.33^{* * *}$ \\
\hline chooling $_{i}=$ schooling $_{j}$ & 1.1 \\
\hline ountry of birth ${ }_{i}=$ country of birth $h_{j}$ & $2.14^{* * *}$ \\
\hline narried $_{i}=$ married $_{j}$ & $1.27^{*}$ \\
\hline parent $_{j}$ & $1.39^{* * *}$ \\
\hline loyed $_{i}=$ employed $_{j}$ & $1.57^{* * *}$ \\
\hline hs welfare $_{i}-$ months welfc & $1.21^{*}$ \\
\hline days $_{i}-$ sick days $_{j} \mid \leq 14$ day & $001^{*}$ \\
\hline 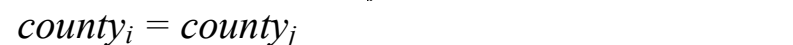 & 26. \\
\hline
\end{tabular}

*** indicates significant at $1 \%$. Data is from Period 1 . 
Table 5. Exogeneity Tests and Robustness Checks.

\begin{tabular}{|c|c|c|}
\hline $\begin{array}{l}\text { Dependent variable }= \\
\text { Nr of crimes }\end{array}$ & $\begin{array}{l}\text { Raw OLS } \\
\text { association }\end{array}$ & 2SLS \\
\hline & \multicolumn{2}{|c|}{ Panel A: Period 1 baseline estimates from Table 3} \\
\hline & 0.189 & 0.167 \\
\hline Peer effects, $\phi$ & \multirow{2}{*}{$(0.002)$} & $(0.004)$ \\
\hline First stage F-stat & & 33 \\
\hline & \multicolumn{2}{|c|}{ Panel B: Model including lagged crime } \\
\hline Peor effects $\widehat{\phi}$ & \multirow{3}{*}{$\begin{array}{c}0.189 \\
(0.002)\end{array}$} & 0.144 \\
\hline Peer ejJects, $\varphi$ & & $(0.004)$ \\
\hline First stage F-stat & & 125 \\
\hline & \multicolumn{2}{|c|}{ Panel C: Random placebo test } \\
\hline & \multirow{3}{*}{$\begin{array}{c}0.000 \\
(0.006)\end{array}$} & 0.002 \\
\hline Peer effects, $\phi$ & & $(0.009)$ \\
\hline First stage F-stat & & 6 \\
\hline & \multicolumn{2}{|c|}{ Panel D: Nonrandom placebo test } \\
\hline & \multirow{3}{*}{$\begin{array}{c}0.028 \\
(0.002)\end{array}$} & 0.001 \\
\hline Peer effects, $\phi$ & & $(0.003)$ \\
\hline First stage F-stat & & 341 \\
\hline & \multicolumn{2}{|c|}{$\begin{array}{c}\text { Panel E: Increase the number of links by } 20 \% \text { by replacing missing } \\
\text { links with highly likely links }\end{array}$} \\
\hline & \multirow{3}{*}{$\begin{array}{c}0.137 \\
(0.002)\end{array}$} & 0.111 \\
\hline Peer effects, $\phi$ & & $(0.003)$ \\
\hline First stage F-stat & & 85 \\
\hline
\end{tabular}

Panel F: Increase the number of links by $11 \%$ by replacing missing links with links that are present in Period 2
Peer effects, $\hat{\phi}$
0.143
(0.002)
0.130
$(0.002)$

First stage F-stat 63

Panel G: Giant component intact

$\begin{array}{ccc}\text { Peer effects, } \hat{\phi} & 0.186 & 0.152 \\ & (0.002) & (0.004)\end{array}$

First stage F-stat 47

Panel H: Alternative algorithm for finding community structures

Peer effects, $\hat{\phi}$

0.185

(0.003)

0.170

(0.004)

First stage F-stat

Panel I: Unweighted estimates

Peer effects, $\hat{\phi}$

0.159

22

(0.002)

0.150

(0.003)

First stage F-stat

42

Standard errors in parentheses. 
Table 6. Correlations Between Four Different Measures of Network Centrality.

\begin{tabular}{|c|c|c|c|c|c|c|c|c|c|}
\hline & \multicolumn{4}{|c|}{ Period 1} & \multicolumn{4}{|c|}{ Period 2} \\
\hline & & Betweenness & Eigenvector & Bonacich & Intercentrality & Betweenness & Eigenvector & Bonacich & Intercentrality \\
\hline \multirow{7}{*}{$\begin{array}{l}\overline{0} \\
\overline{0} \\
0 \\
0\end{array}$} & $\begin{array}{l}\text { Betweenness } \\
\mathrm{N}\end{array}$ & $\begin{array}{c}1.00 \\
15,205\end{array}$ & & & & & & & \\
\hline & Fioenvector & $0.37 *$ & 1.00 & & & & & & \\
\hline & $\mathrm{N}$ & 15,205 & 15,205 & & & & & & \\
\hline & & $0.03 *$ & $-0.06^{*}$ & 1.00 & & & & & \\
\hline & $\mathrm{N}$ & 13,058 & 13,058 & 13,058 & & & & & \\
\hline & Intercentrality & $0.02 *$ & $0.07 *$ & $0.94 *$ & 1.00 & & & & \\
\hline & $\mathrm{N}$ & 13,058 & 13,058 & 13,058 & 13,058 & & & & \\
\hline \multirow{8}{*}{$\begin{array}{l}\text { N } \\
\frac{0}{0} \\
.0 \\
0\end{array}$} & Retweenness & $0.08 *$ & 0.03 & 0.02 & 0.01 & 1.00 & & & \\
\hline & $\mathrm{N}$ & 3,882 & 3,882 & 3,240 & 3,240 & 15,144 & & & \\
\hline & & $0.04 *$ & $0.17^{*}$ & $-0.07 *$ & -0.00 & $0.34 *$ & 1.00 & & \\
\hline & $\mathrm{N}$ & 3,882 & 3,882 & 3,240 & 3,240 & 15,144 & 15,144 & & \\
\hline & Bonacich & 0.02 & -0.01 & $0.09 *$ & $0.06^{*}$ & 0.02 & $-0.02 *$ & 1.00 & \\
\hline & $\begin{array}{l}\mathrm{N} \\
\end{array}$ & 3,168 & 3,168 & 2,739 & 2,739 & 12,769 & 12,769 & 12,769 & \\
\hline & & 0.00 & 0.03 & $0.05 *$ & $0.06^{*}$ & 0.00 & $0.05 *$ & $0.95 *$ & 1.00 \\
\hline & $\mathrm{N}$ & 3,168 & 3,168 & 2,739 & 2,739 & 12,769 & 12,769 & 12,769 & 12,769 \\
\hline
\end{tabular}

* denotes significance at $5 \%$ level. $\mathrm{N}=$ number of observations used to calculate correlation. 
Table 7. Predictions from the Key Player Model.

\begin{tabular}{|c|c|c|c|c|}
\hline Dependent variable & $\begin{array}{l}\text { Average } \\
\text { Reduction }\end{array}$ & $\begin{array}{l}\text { Network } \\
\text { Size }\end{array}$ & $\begin{array}{c}\text { Mean } \\
\text { network } \\
\text { size }\end{array}$ & Sample \\
\hline Key Player: $\frac{100 * d_{i}\left(g_{r}, \widehat{\phi}\right)_{\max }}{B\left(g_{r}, \widehat{\phi}\right)}$ & $\begin{array}{l}37.64 \% \\
(0.139) \\
\end{array}$ & $\begin{array}{c}-0.163 \% \\
(0.001) \\
\end{array}$ & 62 & $\begin{array}{c}\text { All } \\
\mathrm{N}=13,057 \\
\end{array}$ \\
\hline $\begin{array}{l}\frac{100 * d_{i}\left(g_{r}, \widehat{\phi}\right)_{\max }}{B\left(g_{r}, \widehat{\phi}\right)} \\
-\frac{100 * d_{i}\left(g_{r}, \widehat{\phi}\right)_{\text {random }}}{B\left(g_{r}, \widehat{\phi}\right)}\end{array}$ & $\begin{array}{l}14.28 \% \\
(0.121)\end{array}$ & $\begin{array}{c}-0.027 \% \\
(0.001)\end{array}$ & 67 & $\begin{array}{c}\text { Key player } \neq \\
\text { random player } \\
\mathrm{N}=11,830\end{array}$ \\
\hline $\begin{array}{l}\frac{100 * d_{i}\left(g_{r}, \widehat{\phi}\right)_{\max }}{B\left(g_{r}, \widehat{\phi}\right)} \\
-\frac{100 * d_{i}\left(g_{r}, \widehat{\phi}\right)_{\text {most active }}}{B\left(g_{r}, \widehat{\phi}\right)}\end{array}$ & $\begin{array}{l}12.79 \% \\
(0.130)\end{array}$ & $\begin{array}{c}-0.026 \% \\
(0.001)\end{array}$ & 73 & $\begin{array}{l}\text { Key player } \neq \\
\text { most active } \\
\mathrm{N}=10,638\end{array}$ \\
\hline $\begin{array}{l}\frac{100 * d_{i}\left(g_{r}, \widehat{\phi}\right)_{\text {max }}}{B\left(g_{r}, \widehat{\phi}\right)} \\
-\frac{100 * d_{i}\left(g_{r}, \widehat{\phi}\right)_{\text {highest betweenness }}}{B\left(g_{r}, \widehat{\phi}\right)}\end{array}$ & $\begin{array}{l}7.16 \% \\
(0.120)\end{array}$ & $\begin{array}{l}0.006 \% \\
(0.002)\end{array}$ & 75 & $\begin{array}{c}\text { Key player } \neq \\
\text { highest } \\
\text { betweenness } \\
\mathrm{N}=8,256\end{array}$ \\
\hline $\begin{array}{l}\frac{100 * d_{i}\left(g_{r}, \widehat{\phi}\right)_{\max }}{B\left(g_{r}, \widehat{\phi}\right)} \\
-\frac{100 * d_{i}\left(g_{r}, \widehat{\phi}\right)_{\text {highest eigenvector }}}{B\left(g_{r}, \widehat{\phi}\right)}\end{array}$ & $\begin{array}{c}3.59 \% \\
(0.063)\end{array}$ & $\begin{array}{c}-0.011 \% \\
(0.001)\end{array}$ & 71 & $\begin{array}{c}\text { Key player } \neq \\
\text { highest eigenvector } \\
\mathrm{N}=3,947\end{array}$ \\
\hline
\end{tabular}

Standard errors in parentheses. 
Table 8. Actual Reductions in Crime in Period 2 After Removing the Key Player (in \%).

\begin{tabular}{|c|c|c|c|c|}
\hline Type $-X$ player $=$ & $\begin{array}{l}\text { Random } \\
\text { player }\end{array}$ & $\begin{array}{l}\text { Most } \\
\text { active } \\
\text { player }\end{array}$ & $\begin{array}{l}\text { Player with } \\
\text { highest } \\
\text { betweenness } \\
\text { centrality }\end{array}$ & $\begin{array}{l}\text { Player with } \\
\text { highest } \\
\text { eigenvector } \\
\text { centrality }\end{array}$ \\
\hline & \multicolumn{4}{|c|}{ Panel A: estimated coefficients } \\
\hline Key player removed & $\begin{array}{c}16.13 \\
(0.861)\end{array}$ & $\begin{array}{c}7.34 \\
(0.542)\end{array}$ & $\begin{array}{c}8.62 \\
(0.688)\end{array}$ & $\begin{array}{c}11.53 \\
(1.471)\end{array}$ \\
\hline Type-X player removed & $\begin{array}{c}9.73 \\
(0.717)\end{array}$ & $\begin{array}{c}4.91 \\
(0.738)\end{array}$ & $\begin{array}{c}2.30 \\
(0.771)\end{array}$ & $\begin{array}{c}-6.24 \\
(1.330)\end{array}$ \\
\hline $\begin{array}{l}\text { Key player removed } \\
\text { \& type-X player removed }\end{array}$ & $\begin{array}{c}9.50 \\
(0.997)\end{array}$ & $\begin{array}{c}22.13 \\
(0.890)\end{array}$ & $\begin{array}{c}20.84 \\
(0.979)\end{array}$ & $\begin{array}{c}28.58 \\
(1.862)\end{array}$ \\
\hline Network size & $\begin{array}{c}-0.06 \\
(0.003)\end{array}$ & $\begin{array}{c}-0.03 \\
(0.003)\end{array}$ & $\begin{array}{l}-0.06 \\
(0.003)\end{array}$ & $\begin{array}{l}-0.07 \\
(0.005)\end{array}$ \\
\hline \multirow[t]{2}{*}{ Constant } & $\begin{array}{c}46.74 \\
(0.591) \\
\end{array}$ & $\begin{array}{c}51.77 \\
(0.476) \\
\end{array}$ & $\begin{array}{c}54.33 \\
(0.604) \\
\end{array}$ & $\begin{array}{c}55.08 \\
(1.104) \\
\end{array}$ \\
\hline & \multicolumn{4}{|c|}{ Panel B: baseline results } \\
\hline $\begin{array}{l}\text { Actual difference: } \\
\text { key player removed- } \\
\text { type-X player removed }\end{array}$ & $\begin{array}{c}6.41 \\
(0.740)\end{array}$ & $\begin{array}{c}2.43 \\
(0.758)\end{array}$ & $\begin{array}{c}6.33 \\
(0.758)\end{array}$ & $\begin{array}{l}17.78 \\
(1.386)\end{array}$ \\
\hline $\begin{array}{l}\text { Predicted difference } \\
\text { from Table } 7\end{array}$ & $\begin{array}{c}14.28 \\
(0.121) \\
\end{array}$ & $\begin{array}{c}12.79 \\
(0.130)\end{array}$ & $\begin{array}{c}7.16 \\
(0.120) \\
\end{array}$ & $\begin{array}{c}3.59 \\
(0.063) \\
\end{array}$ \\
\hline \multirow[b]{2}{*}{$\begin{array}{l}\text { Actual difference: key player } \\
\text { removed-type-X player } \\
\text { removed }\end{array}$} & \multicolumn{4}{|c|}{ Panel C: dead, emigrated or in prison } \\
\hline & $\begin{array}{c}17.52 \\
(10.43)\end{array}$ & $\begin{array}{c}2.42 \\
(10.05)\end{array}$ & $\begin{array}{c}9.19 \\
(14.64)\end{array}$ & $\begin{array}{c}25.81 \\
(19.12)\end{array}$ \\
\hline & \multicolumn{4}{|c|}{ Panel D: no crime, 2003-2008 } \\
\hline $\begin{array}{l}\text { Actual difference: key player } \\
\text { stops crime - type-X player } \\
\text { stops crime }\end{array}$ & $\begin{array}{c}4.65 \\
(1.911)\end{array}$ & $\begin{array}{c}1.95 \\
(1.984)\end{array}$ & $\begin{array}{c}4.57 \\
(1.919)\end{array}$ & $\begin{array}{l}19.78 \\
(3.615)\end{array}$ \\
\hline Sample size & 11,830 & 10,638 & 8,256 & 3,947 \\
\hline Mean network size & 67 & 73 & 75 & 71 \\
\hline
\end{tabular}

Dependent variable $=\%$ crime reduction in each network. Standard errors in parentheses. 
Degree Distribution in Period 1

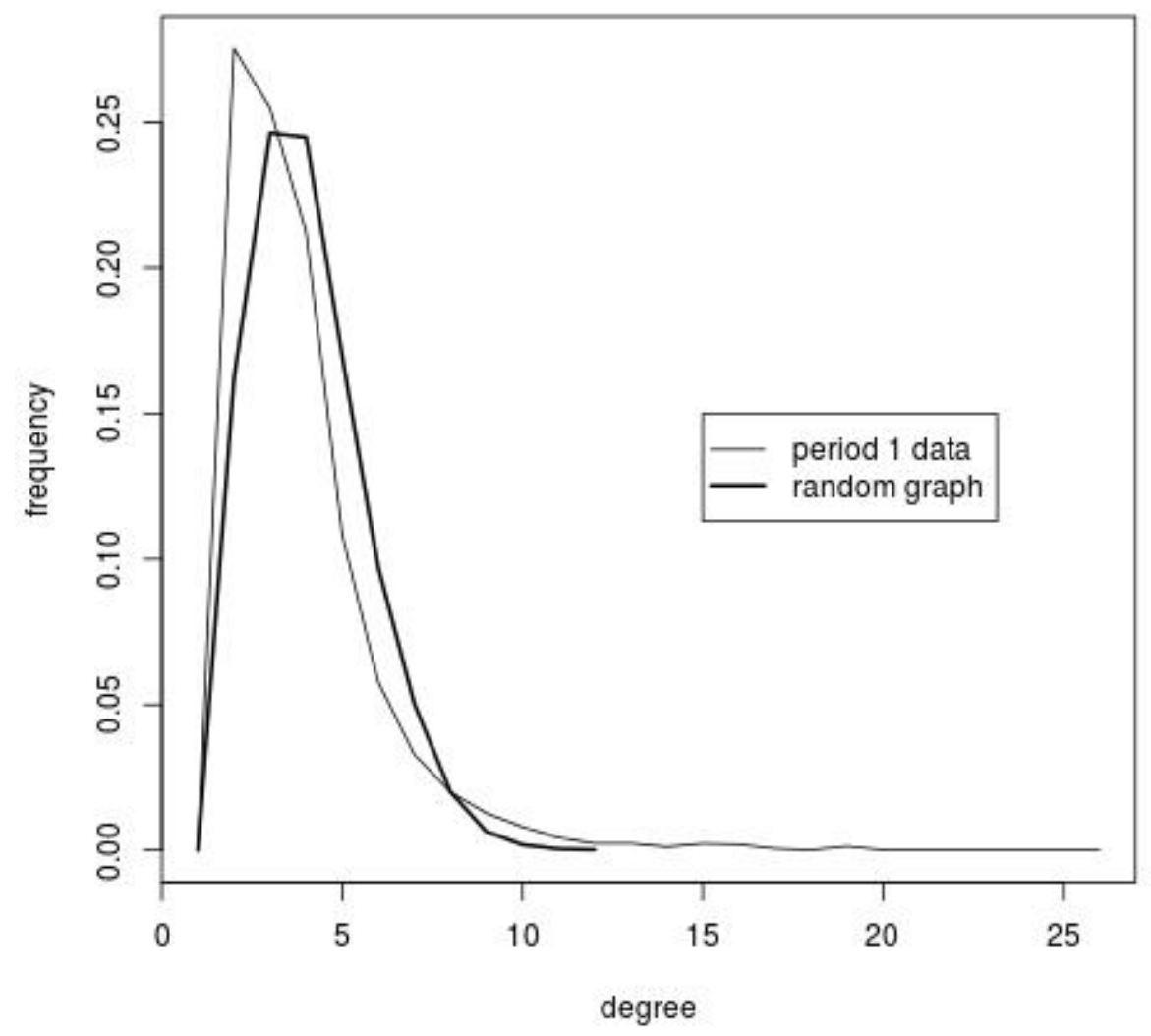




\section{Degree Distribution in Period 2}

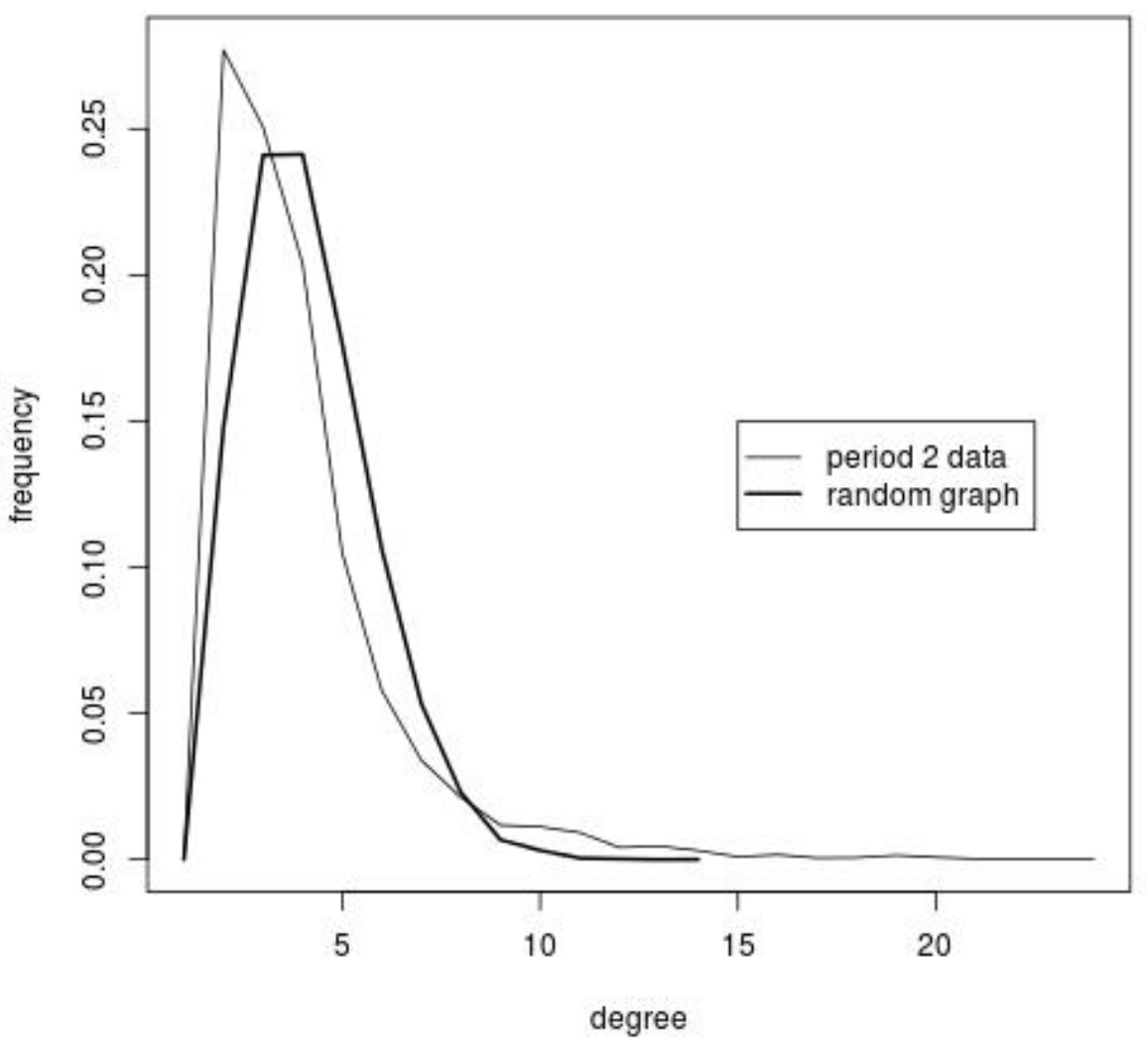



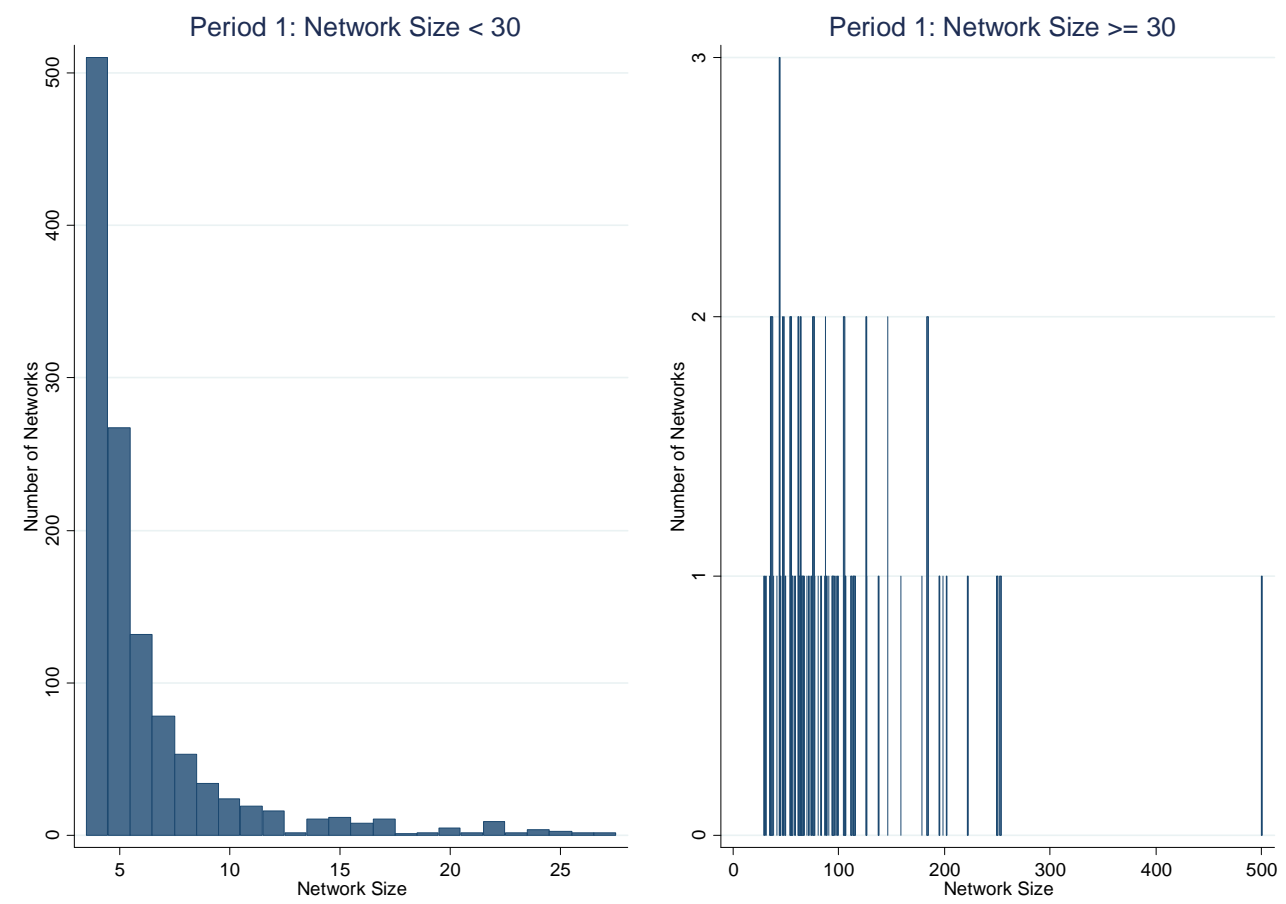

Figure 3. Distribution of Networks by Network Size. 

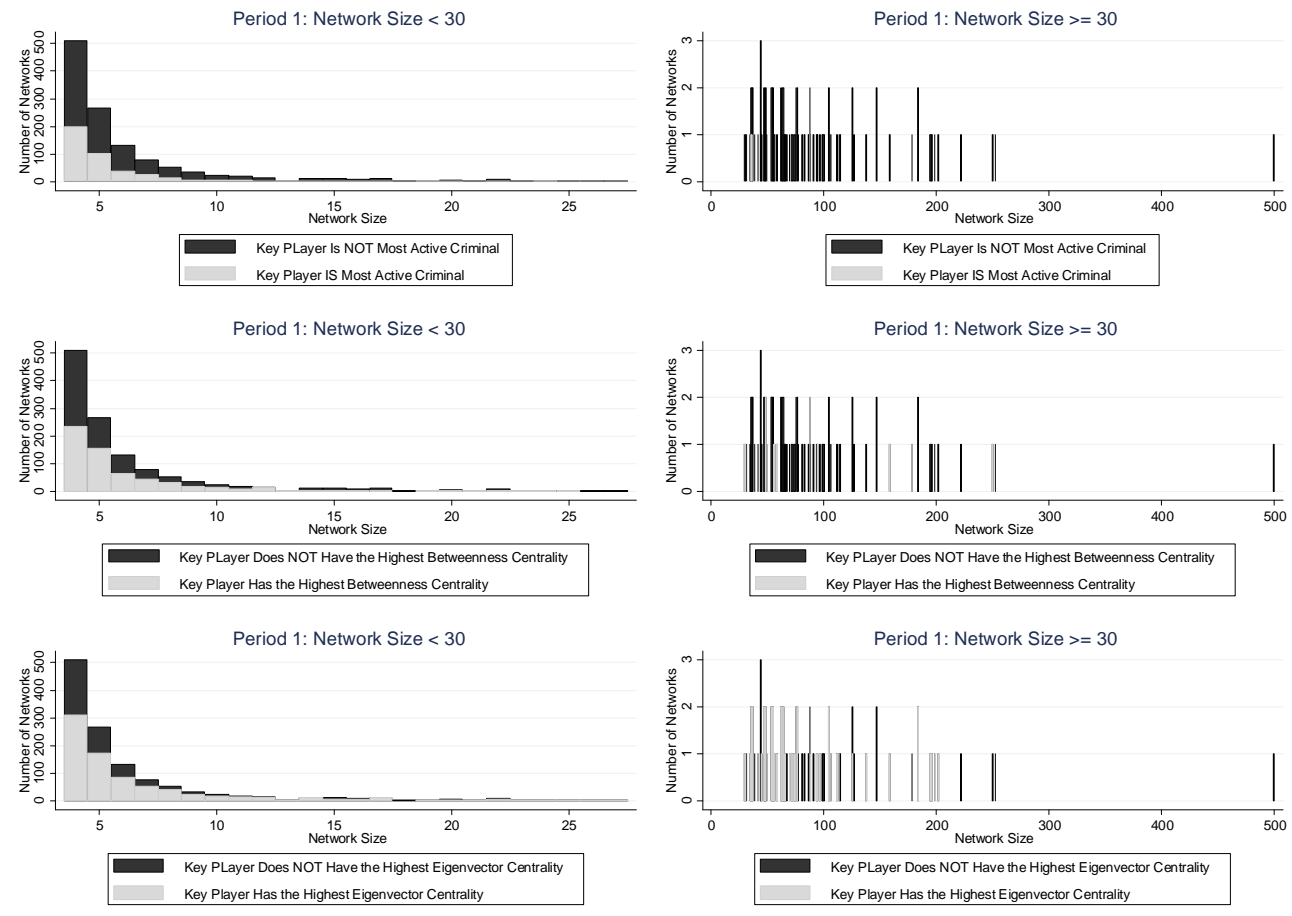

Figure 4. Key Player Is Not Type- $x$ Player, by Network Size. 